\section{Journal of Home \\ Economics}

http://homeEcon.menofia.edu.eg

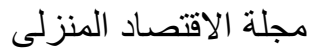

مجلد 27- عدد يوليو - 2017م مجنياد

\title{
فعالية برنامج مقترح قائم على أشغال الإبرة لتنمية التحصيل و القيم الجمالية لاى تلاميذ المرحلة الإن الابتدائية

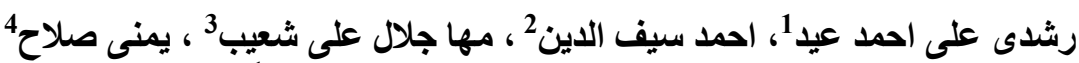

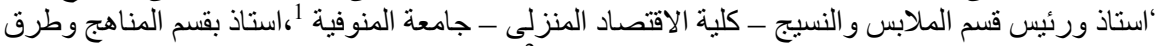

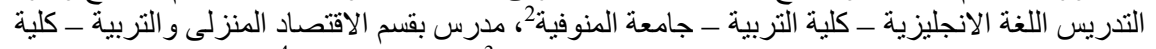 الاقتصاد المنزلى - جامعة المنوفية 3 ، باحثة ماجستير 4
}

ملخص البحث

هدف البحث إلى التعرف على فعالية أثخال الإبرة (الكروشيه) في تتمية التحصيل و القيم الجمالية لاى تلاميذ المرحلة الابتدائية.

ولتحقيق أهداف البحث نم اختيار عينة من تلاميذ الصفية الصفية السادس الإبندائى بمدرسة

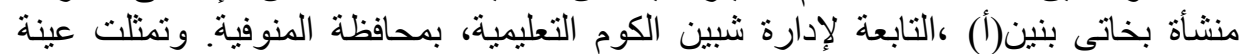

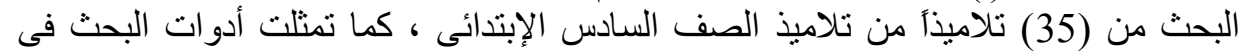

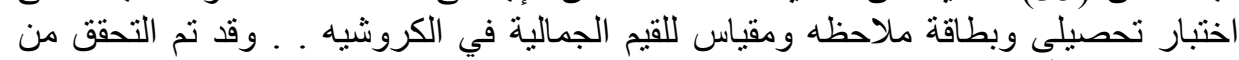

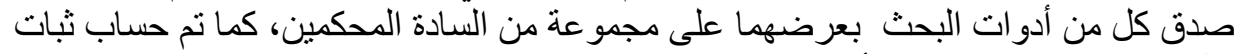

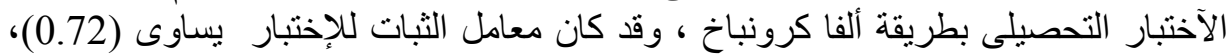

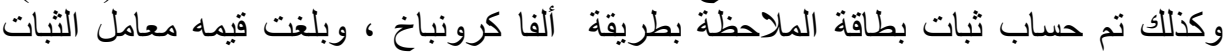

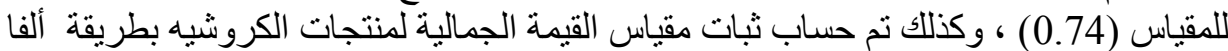

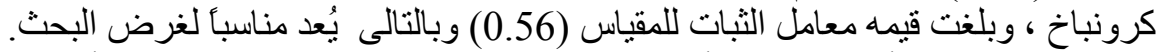

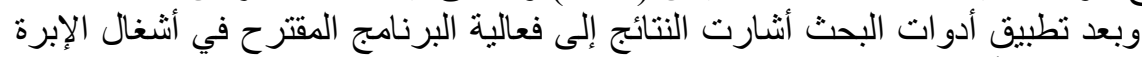

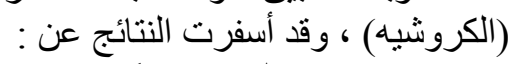

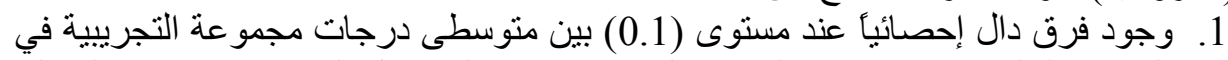
التطبيق القبلى ودرجاتهم في التطبيق البعدى لاختبار التحصيل المعرفى بـى بمستوياته لصالح 2. وجود فرق دال إحصائيًا عند مستوى (0.01) بين متوسطى درجات مجمو عة البعة التجريبية في التطبيق القبلى ودرجاتهم في التطبيق البعدى لبطاقة الملاحظة 3. المهار ات الأدائية لصالح التطبيق البعدى.

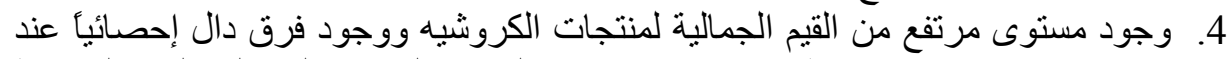

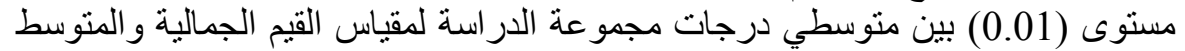
الفرضي لصالح متوسط الدرجات الفين الفعلي.

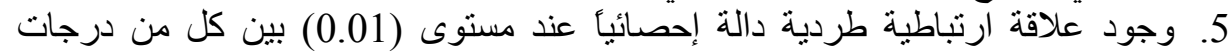

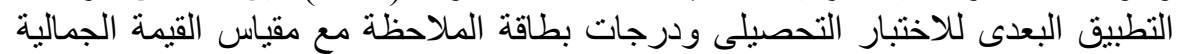

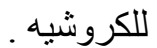
كلمات مفتاحية :أشغال الإبرة، كروشيه، تحصيل، قيم جمالية 


\section{مجلة الاقتصاد المنزلي ـ مجلا 27- العدد الثالث - 2017م}

\section{المقدمة ومشكلة البحث}

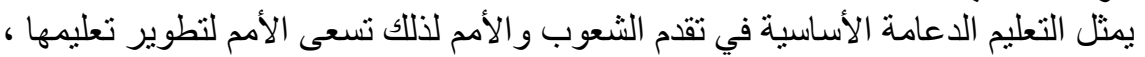

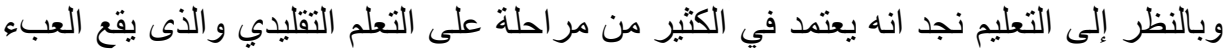

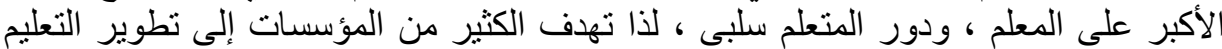

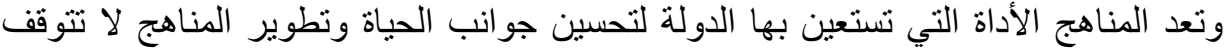

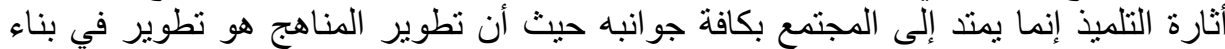

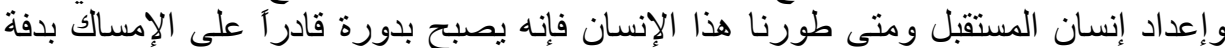

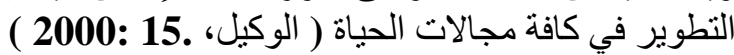

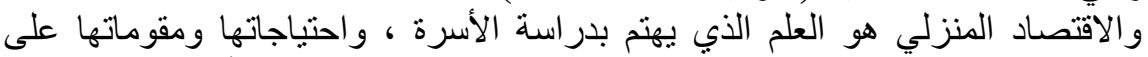
مستوى المنزل والبيئة و المجتمع بقصد النهوض بها إلى حياة عائلية أفضل( كوجلك ، الأل

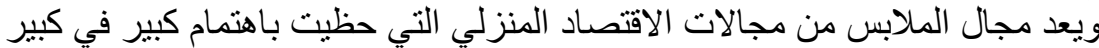

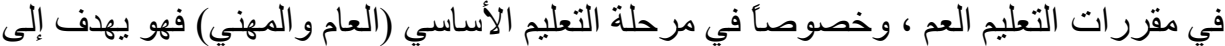

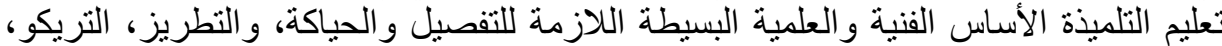

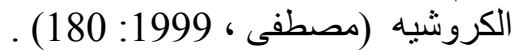
تعتبر أشغال الإبرة من أقدم وأجمل الفنون التي عرفها الإنسان لما لها من أثراء الناحية

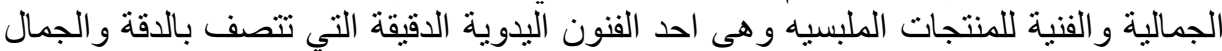

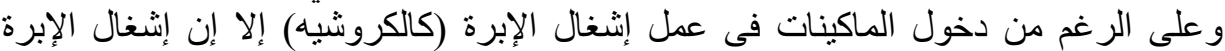

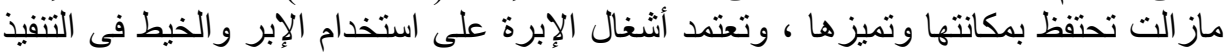

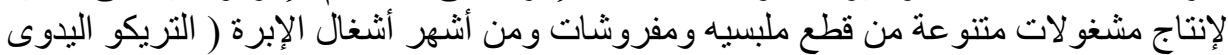

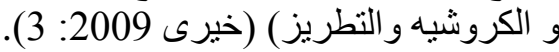

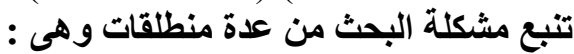

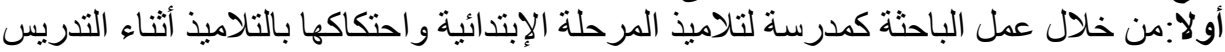

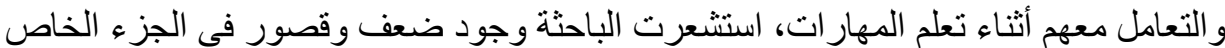

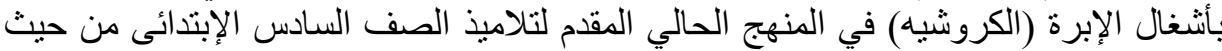

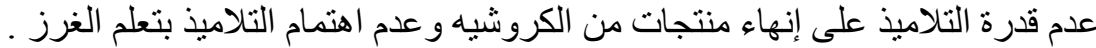

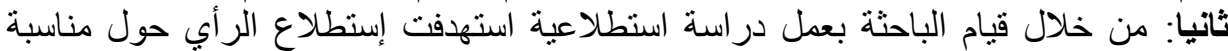

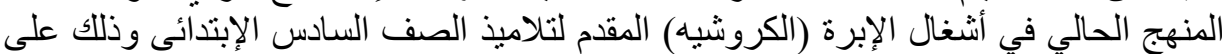

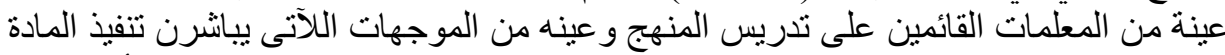

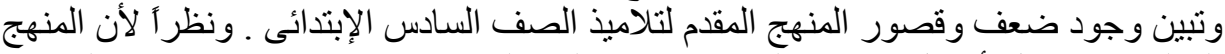

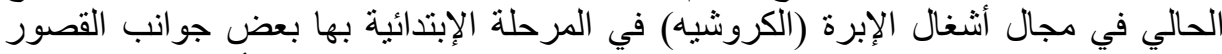

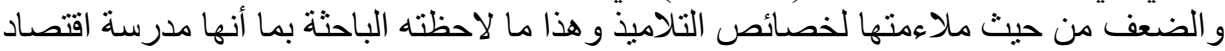

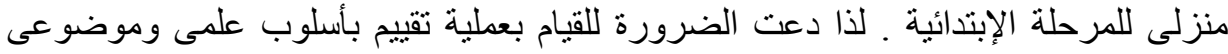

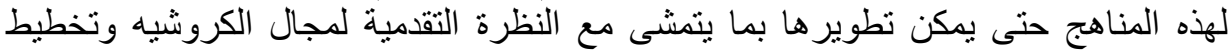

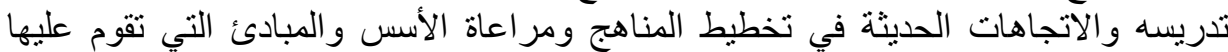

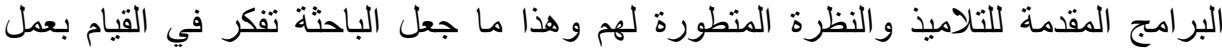

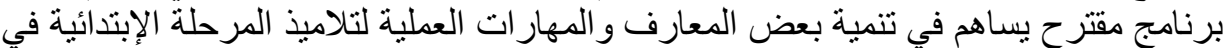

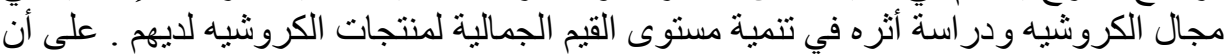




\section{مجلة الاقتصاد المنزلي ـ مجلا 27- العدد الثالث - 2017م}

يقوم البرنامج على أسس علمية منهجية وير اعى أن تكون أهداف البرنامج ملائمة لهذه المرحلة

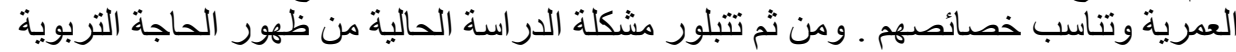

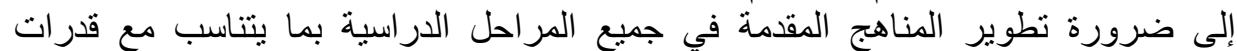

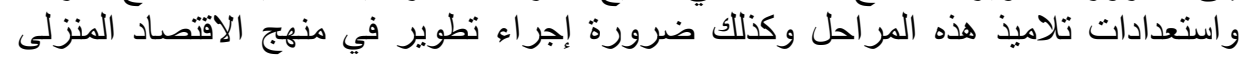

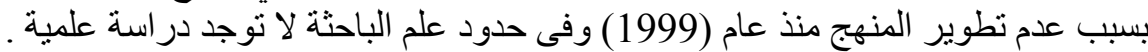
تناولت تطوير منهج الكروشيه لتناميذ المرحلة الإبندائية .

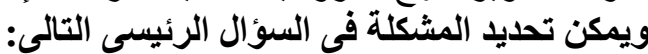

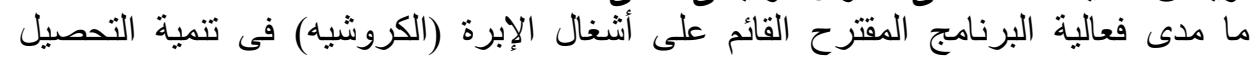

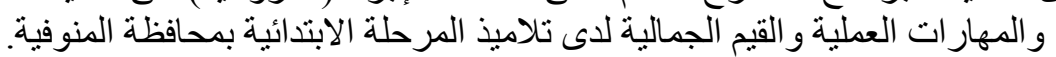

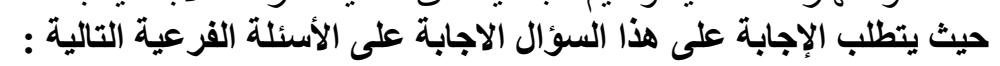

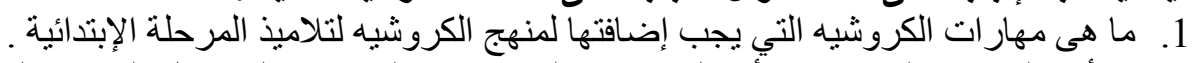

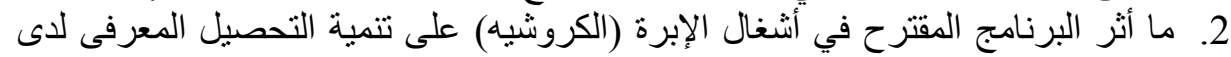
تاميذ المرحلة الإبتدائية .

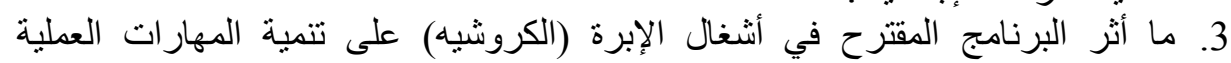
للكروشيه لدى تلاميذ المرحلة الئر الإبتدائية . 4. ما أثر البرنامج المقترح في أثنغال الإبرة (الكروشيه) على تنمية القيم الجمالية لمنتجات الكروشيه الخاصة بعينة الدر استة. 5. هل نوجد علاقة إرتباطية بين بين كل من الجانب المعرفى و المهارى و الجمالى للكروشيه . أهداف البحث

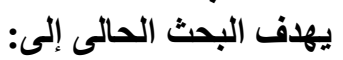
1. إعداد برنامج مقترح في مجال أنثغال الإبرة (الكروشيه) لتلاميذ المرحلة الإبتدائية يقوم

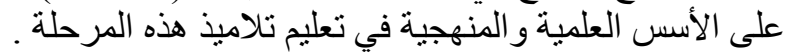

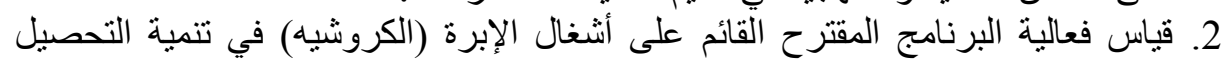

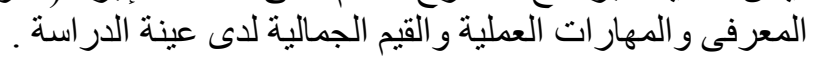

1. محاولة الإسهام في تحقيق أهداف التعليم الإبتدائى من حيث تنمية المهارات العملية لدى

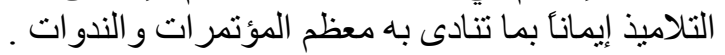

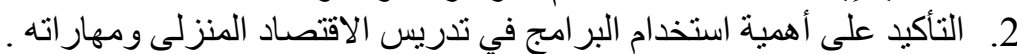

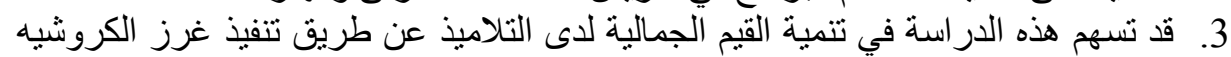

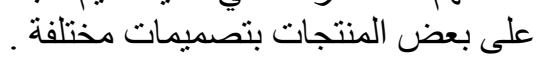
4. قد تسهم هذه الدراسة في رفع كفاءة التلاميذ في بعض مهارات الكروشيه مع تقليل الفاقد

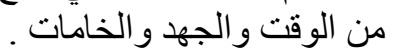

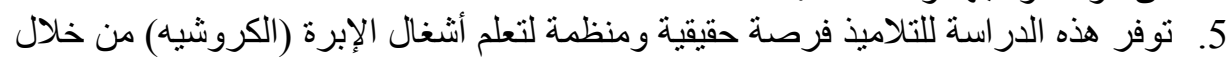

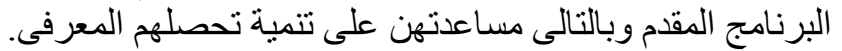

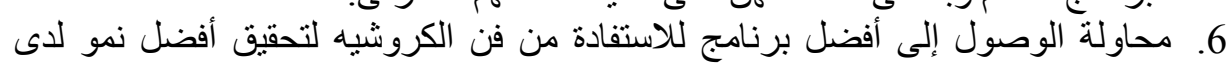

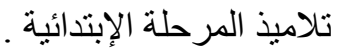




\section{مجلة الاقتصاد المنزلي - مجلد 27- العدد الثالث - 2017م}

حدود البحث البحث الإلى عالى الحدود التالية.

يقتصر البحث الحالى على الحدود التالية: 1. (حدود بشرية) تتحدد الدراسة بتلاميذ الصف السفة السادس الإبتدائى.

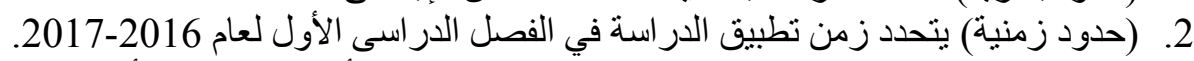
3. (حدود المكانية) يتحدد مكان تطبيق الدر اسة في مدرسة منشأة بخاتى بنين ( أ ) بمحافظة

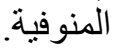

4. (حدود موضوعية) نوظيف بعض فنون أشغال الإبرة (الكروشيه) و التحصيل المعرفى والمهارات العملية والقيم الجمالية للكروشيه. أدوات البحث

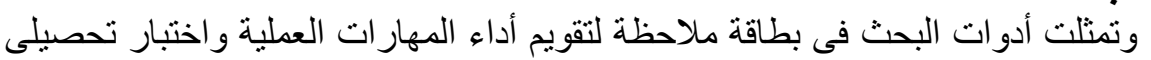

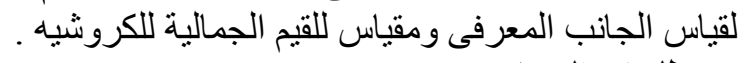
مصطلحات البحث فاعلية (Effectiveness)

وتعرف إجرائياً على أنها: مدى الأثر الذى يحدثه البرنامج المقترح باستخدام أشغال

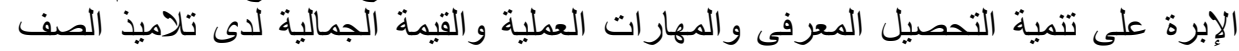

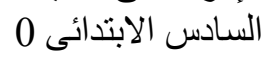

(البرنامج -: : (Program)

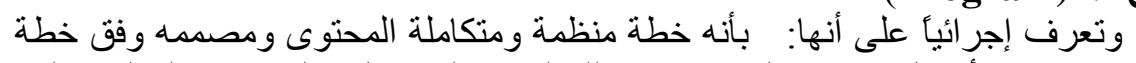

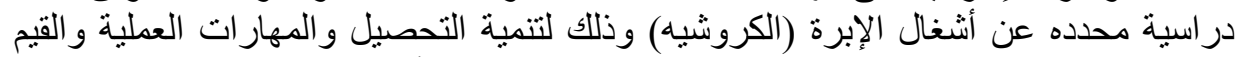

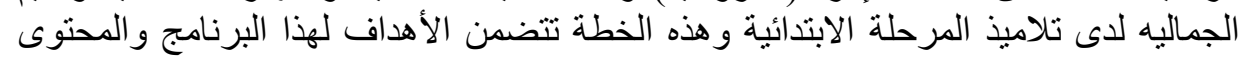

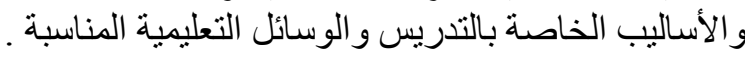

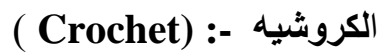

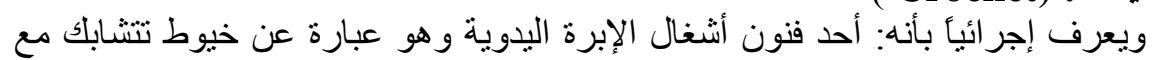

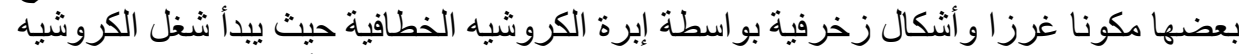

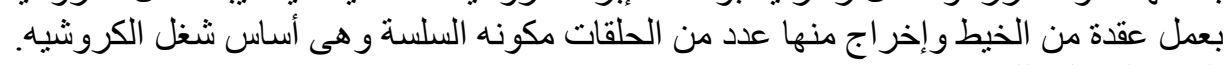

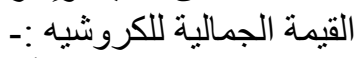
ويعرف إجرائياً بأنه: بأنها القيم والنماذج التي تظهر في الإنتاج الفني للكروشيه ويمكن

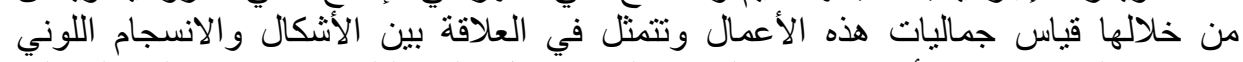

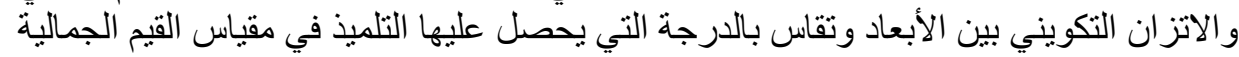

$$
\text { للكروشيه" . الأنظران }
$$

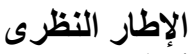

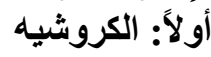

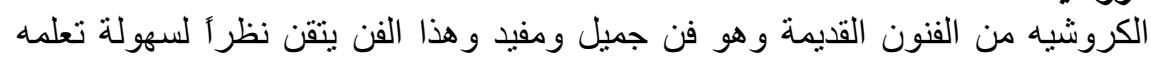

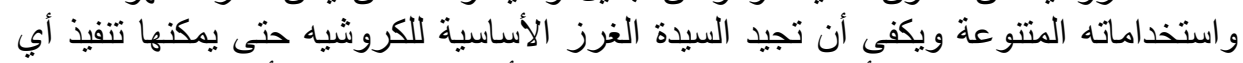

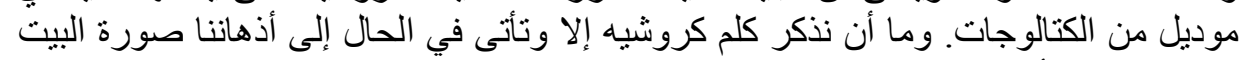

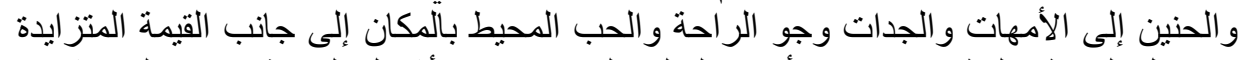

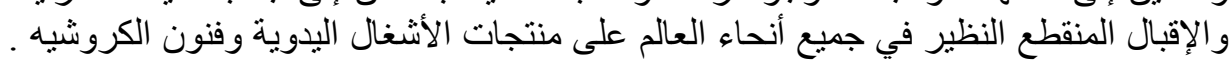




$$
\text { مجلة الاقتصاد المنزلي - مجلا 27- العدد الثالث - 2017م }
$$

ويتناول هذا الفصل الإطار العام للدراسة والدراسات السابقة من حيث استعر اض ( أشغال

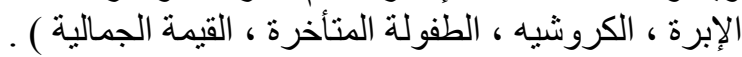

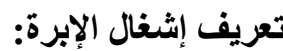

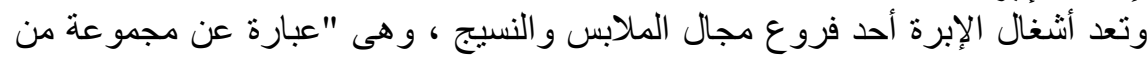

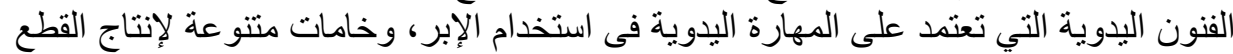

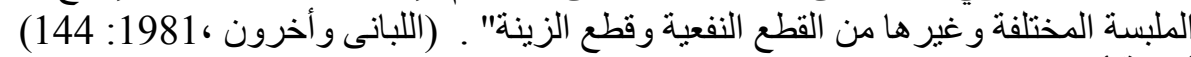

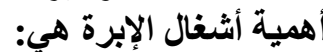
1. إكساب التلميذات بعض الإبرة الخبرات فى أعمال الخياطة المختلفة التي تتناسب مع بيئاتهن

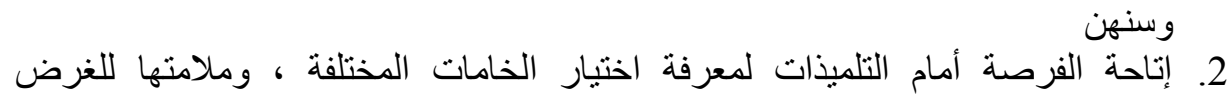

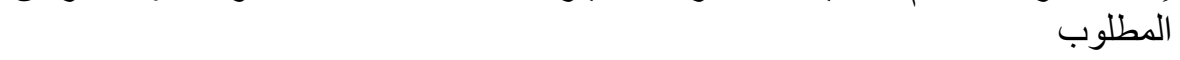
3. تدريب التلميذات على الدقة فى العمل وقوة الملاحظة مع حسن التصرف مما بساعدهن على السر عة في العمل وكثرة الإنتاج .

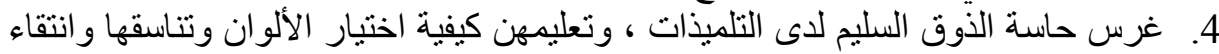

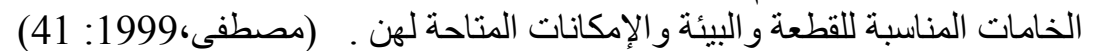

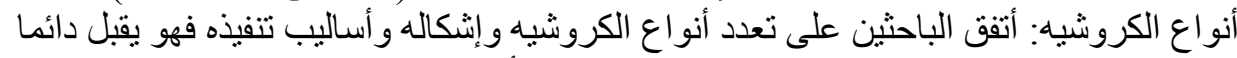

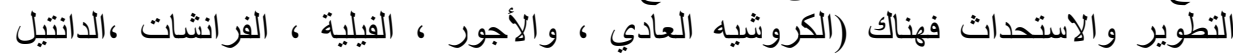

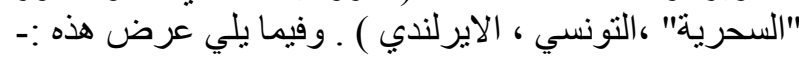

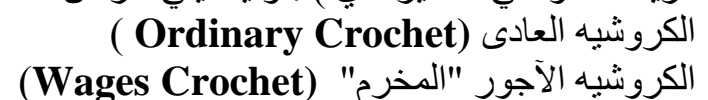

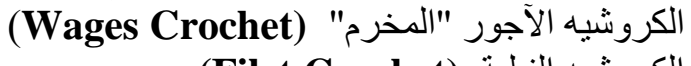

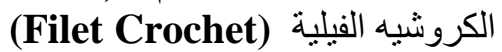

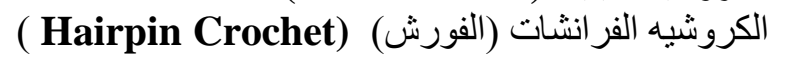

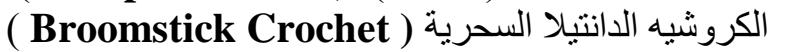

الكروشيه التونسي (Tunisian Crochet)

(Irish Crochet) الكروشيه الايرلنديه

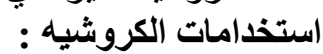

إن الكروشيه من الفنون الراقية الجميلة التي يمكن الابتكار فيها بواسطة الخامات

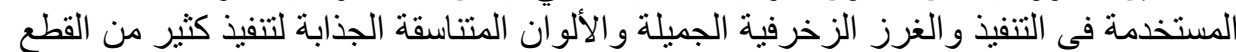

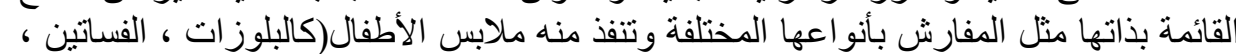

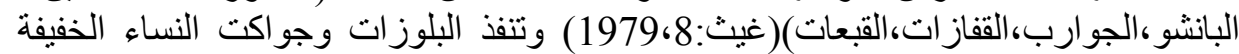

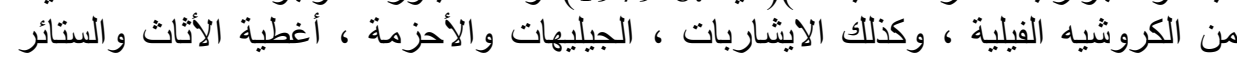

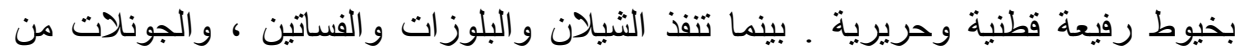
كروشيه الدانتيل و الاجور بخيوط حريرية وقطنية و الحقائب بخيوط المكرمية الرفيعة أو القيطان (المهدى: 1989،9:8).

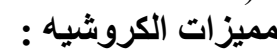
1. يعتبر الكروشيه مسلى فى السفر حيث يمكن انتاج العديد من المشغولات الفنية فى رحلات

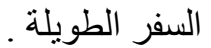


مجلة الاقتصاد المنزلي - مجلد 27- العدد الثالث - 2017م

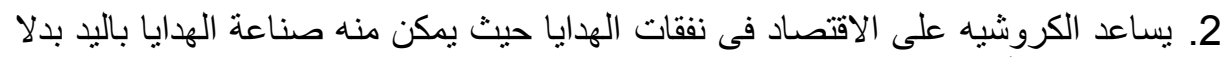
من شر ائها بأسعار مكلفة . 3. لا يتلف الكروشيه بسهولة حيث يكون العمر الاستهلاكي له أكبر من العمر الاستهلاكي

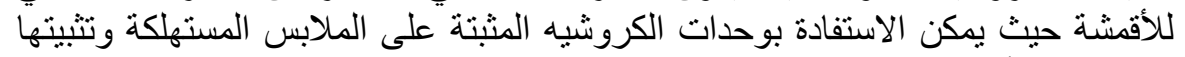

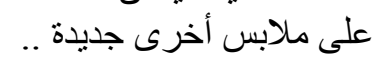
أنواع إبر الكروشيه ملابيه

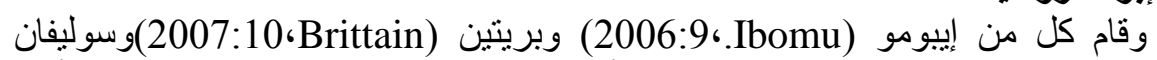
(2008:10،Sullivan) كما هو موضح بالجدول التالى :المقاييس المختلفة لإبر الكروشيه (1) (1) - (1)

\begin{tabular}{|c|c|c|c|c|}
\hline المقاس المتري (مم) & للإبر الألومنيوم & لكالإبر الألمومنيوم / الكنديوم & للإبر المعدن المتري & $\begin{array}{c}\text { u.s. size range } \\
\text { للإبر المعدن }\end{array}$ \\
\hline 2.25 & $\mathrm{~B} / \mathbf{1}$ & 13 & mm 85. & 14 \\
\hline 2.75 & $\mathrm{C} / 3$ & - & mm1.1 & 11 \\
\hline 3.25 & D/3 & 10 & mm1.4 & 9 \\
\hline 3.5 & $E / 4$ & 9 & mm1.5 & 8 \\
\hline 3.75 & F/5 & - & mm1.65 & 7 \\
\hline 4.00 & G/6 & 8 & mm1.8 & 6 \\
\hline 5.0 & H/8 & 6 & mm2.0 & 4 \\
\hline 5.5 & $I / 9$ & 5 & mm2.1 & 3 \\
\hline 6.0 & $\mathbf{J} / \mathbf{1 0}$ & 4 & mm2.25 & 2 \\
\hline 6.5 & $\mathrm{~K} / \mathbf{1 0}$ & 3 & $\mathrm{~mm} 2.75$ & 1 \\
\hline 9.0 & $\mathrm{~N} / 13$ & 00 & - & - \\
\hline 10.0 & $\mathrm{P} / 15$ & 000 & - & - \\
\hline
\end{tabular}

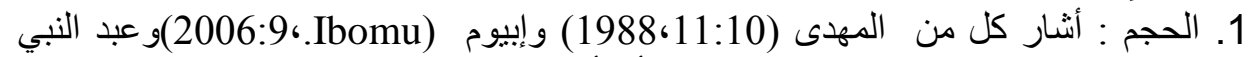
(45 :2007) و الحنفى (2009: 29) إلى أن أحجام إبر الكروشيه مختلفة والذئى يحدد رقم الإبرة المستخدمة هو سمك الخيط :

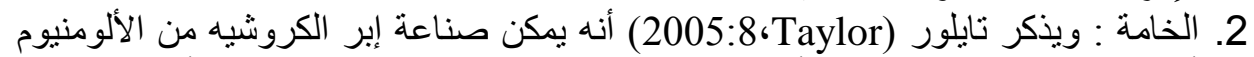
أو الصلب وكذلك الخشب إلا أن الإبر المصنوعة من الخد الخشب يتوافر منها الأحجام الكبيرة فقط . 3. الشكل (إبرة مزدوجة الخطافــ ابر منتظمة)

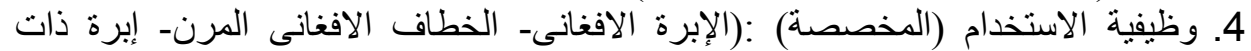
خطاف طويل- إبرة الكنفاة ) أنواع خيوط الكروشيه :

1.

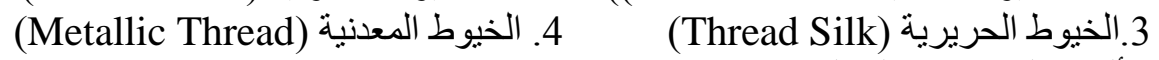
5ynthetic fibers a الألياف الصناعية و المخلوطة الحريرية 


\section{مجلة الاقتصاد المنزلي ـ مجلا 27- العدد الثالث - 2017م}

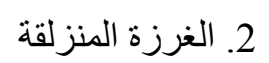

4. الغرز النصف مزدوجة المنزة الغنة

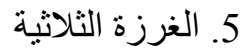

الغزز الأساسية للكروشيه : الغزية

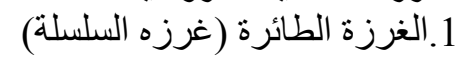

3.الغرزة الفردية البسبطة (الحشو) الطرة)

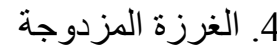

الزيادة و التنقيص في الكروشيه : الكزيه

الزيادة والتنقيص عمليتان هامتان فى تنفيذ أعمال الكروشيه وذللك للأسباب الآتية (سعد

: 66:2008،

1 1. لإعطاء الثنكل المطلوب للقطعة وفقأ للتصميح سواء بالأتساع أو التكسيح .

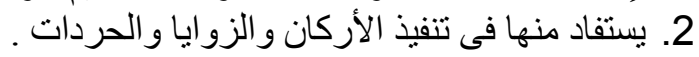

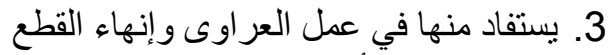

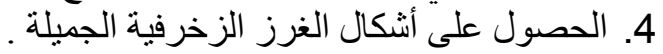

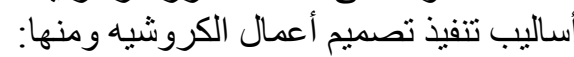

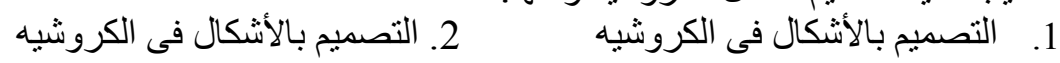

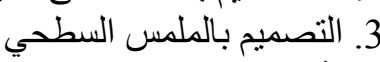

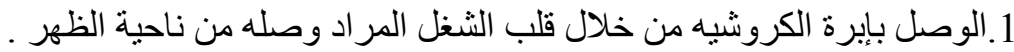

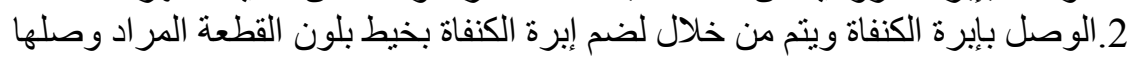
ثانياً: :القيم الجمالية

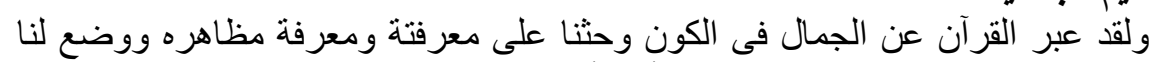

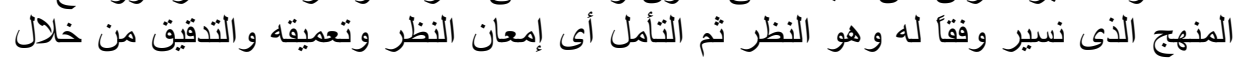

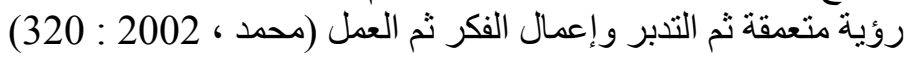
ويذكر عنمان (2008: 169:166) خصائص القيم :

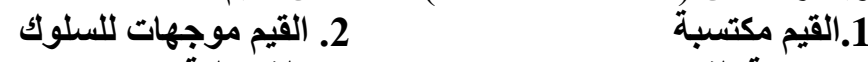

$$
\begin{aligned}
& \text { 3. مرونة القيم }
\end{aligned}
$$

1. المستويات القيم: : مستوى الأوى التقبل ويتضمن الاعتقاد بأهمية قيمة معينة وهى أدنى درجات اليقين

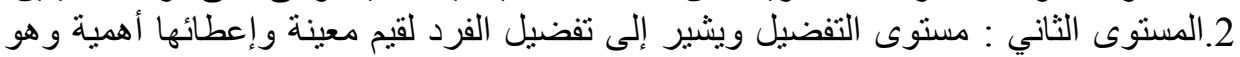

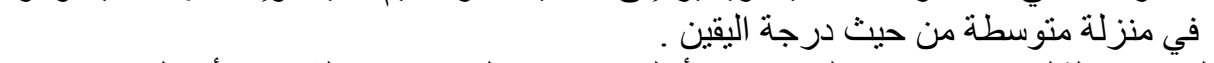

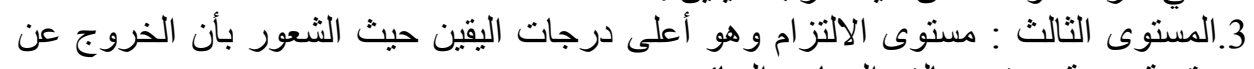
قيمة معينة سوف يخالف المعايير السائدة .
سبر انجر قسم القيم إلى عدة أقسام هي كما ذكر ها عثمان (2008: 170:169): 2. 2. القيم الاقتصادية

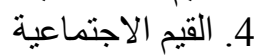
5. - 5 القيم الدينية

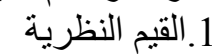

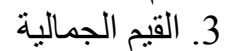

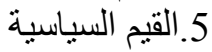




\section{مجلة الاقتصاد المنزلي ـ مجلد 27- العدد الثالث - 2017م}

العوامل التي تؤثر على تحقيق القيمة الجمالية :

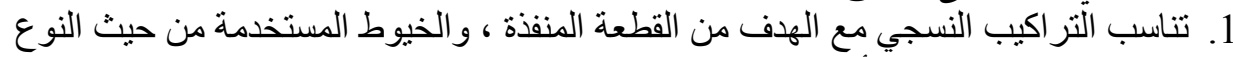

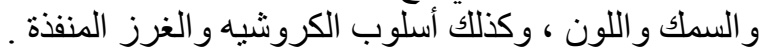

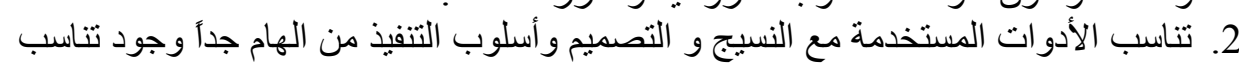

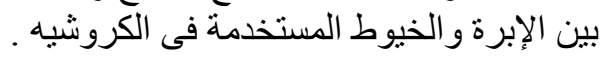

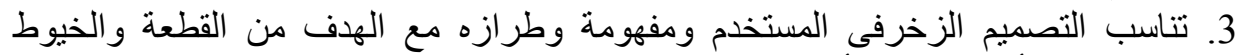

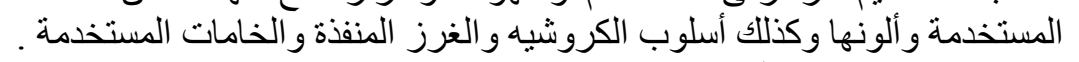

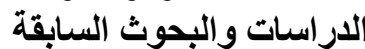

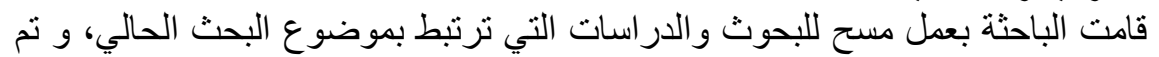

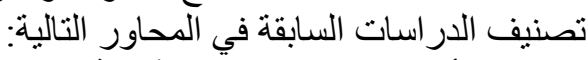
المحور الأول : دراسات تناولت فعالية برامج لتعلم التمالية الكروشيه.

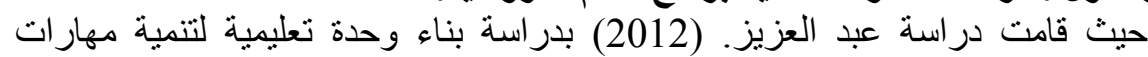

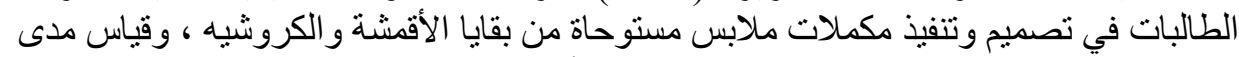

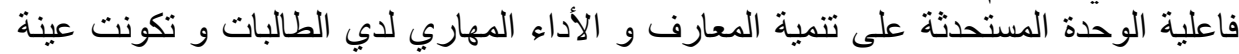

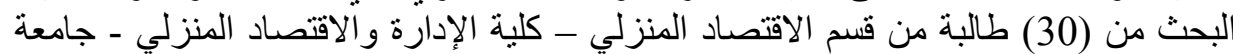

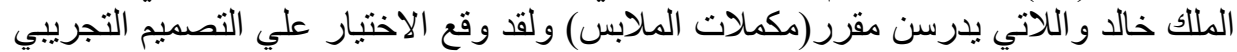

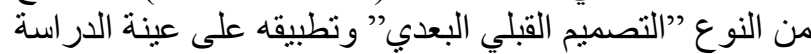

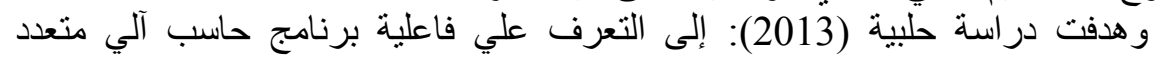

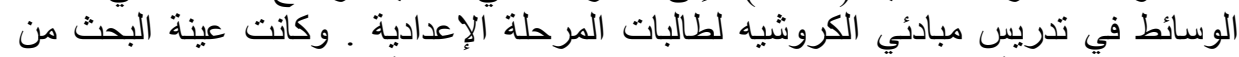

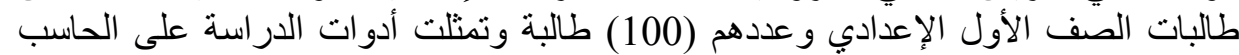

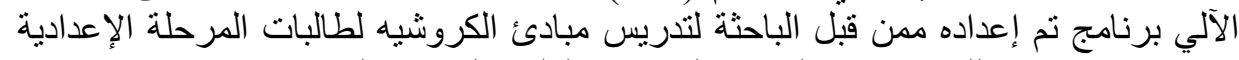

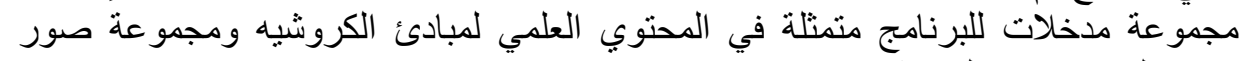
وفيديو لبعض غرز الكروشيه

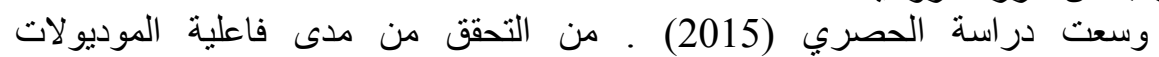

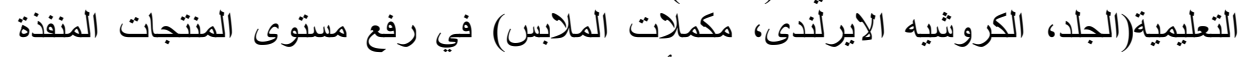

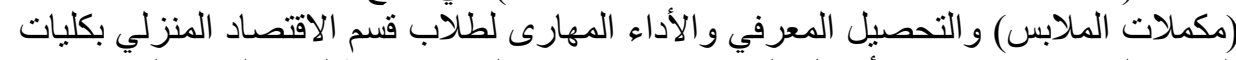

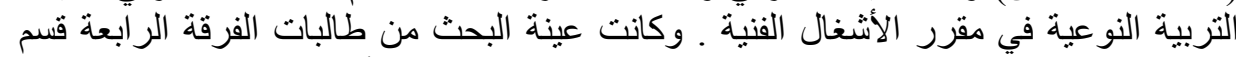

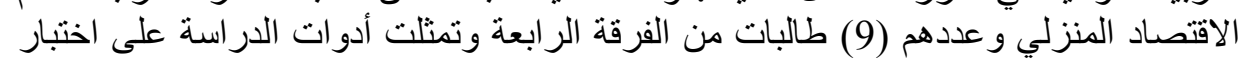

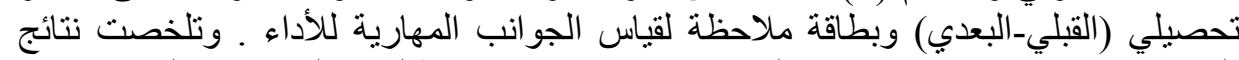

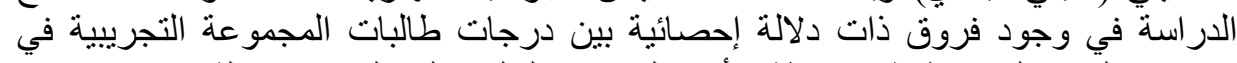

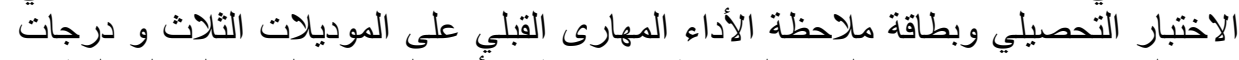

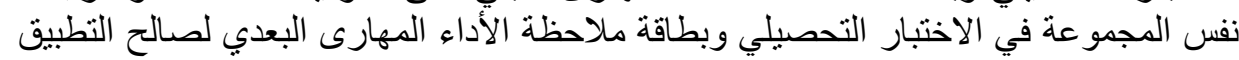

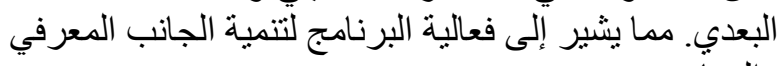

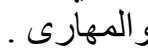
التعقيب على دراسات المحور الأول :

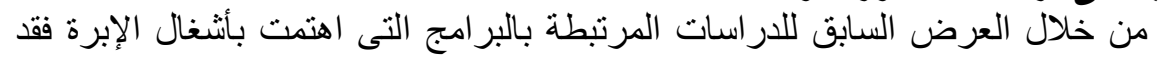

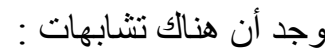




\section{مجلة الاقتصاد المنزلي ـ مجلا 27- العدد الثالث - 2017م}

الاتفاق بين دراسة عبد الله (1994) و و مصطفى (2012) (1999) و دارسه شاهين (2007) و العزيز (2012) و حليبه (2018) و الحصرى (2015) في بناء وحدة تعليمية في الكروشيه

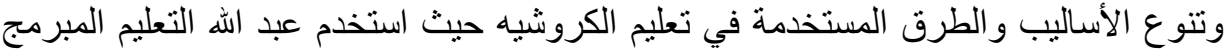

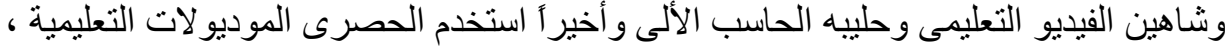

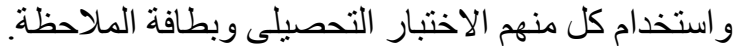

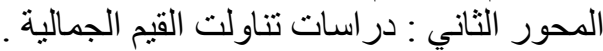

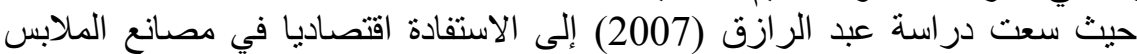

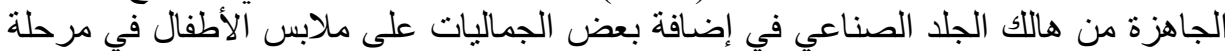

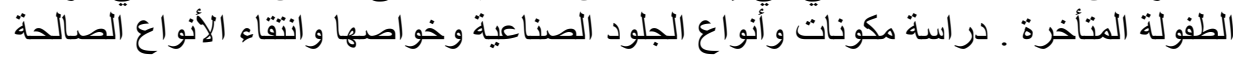

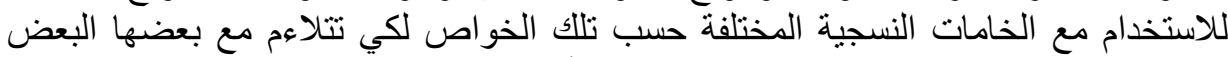
إضافة قيمة جمالية لملابس في مرحلة الطفولة المتأخرة . وسعت دراسة الفقي (2013) إلى التعرف على على نوعية بقايا الأقمشة التي يمكن استخدامها

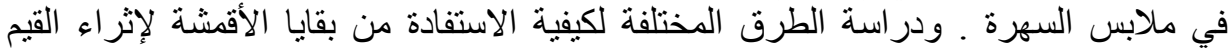

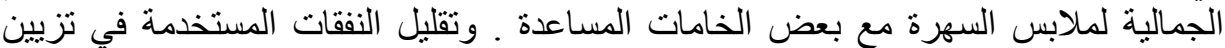

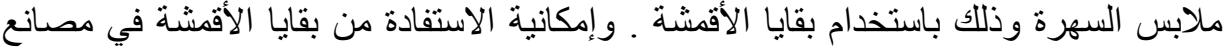

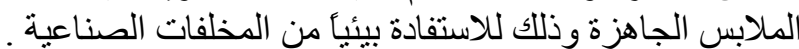

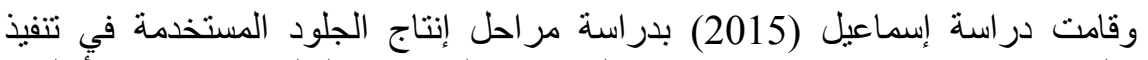

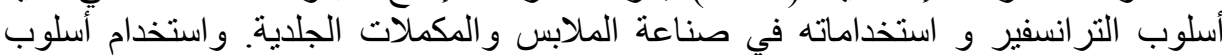
الترانسفير علي أسطح الجلود الطبيعية والصناعية وإعطاء قيمة مظهرية غير تقليدية للجلود

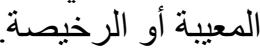
التعقيب على دراسات المحور الثاني :

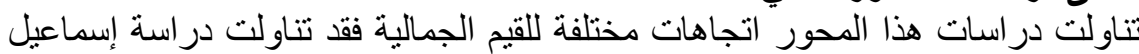

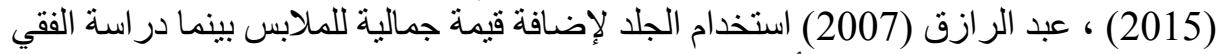

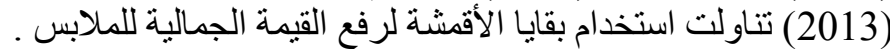

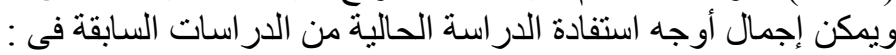

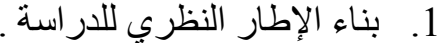
2. الاستفادة في بناء أدوات الدراسة من اختبار ات تحصيلية وبطاقات للملاحظة ومقياس القيم

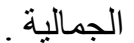

3. تحديد خطوات إعداد وتنفيذ دروس البرنامج القائم على أثنال الإبرة لتنمية التحصيل

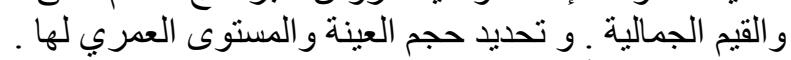
4. الاستفادة من الأساليب الإحصائية التي اتبعت في هذه الدر استات في تحليل وتفسير النتائج . فروض البحث فى ضوء مشكلة الدر اسة و الإطار النظرى وما أسفرت عنه نتائج الدراسات السابقة يمكن صياغة فروض الدراسة وذلك على النى النحو التالى:

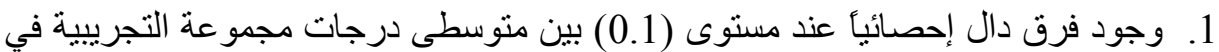
التطبيق القبلى ودرجاتهم في التطبيق البعدى لاختبار التحصيل المعرفى بمستو ياته لصالح

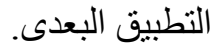




\section{مجلة الاقتصاد المنزلي ـ مجلا 27- العدد الثالث - 2017م}

2. وجود فرق دال إحصائيًا عند مستوى (0.01) بين متوسطى درجات مجمو البوعة التجريبية في التطبيق القبلى ودرجاتهم في التطبيق البعدى لبطاقة الملاحظة البطائ 3. المهار ات الأدائية لصالح التطبيق البعدى.

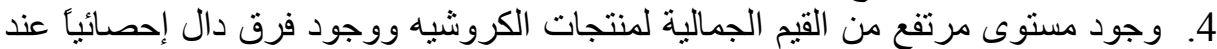
مستوى (0.01) بين منوسطي درجات مجمو عة الدر اسة لمقياس القيم الجمالية و المتوسط

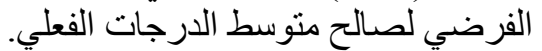
5. وجود علاقة ارتباطية طردية دالة إحصائياً عند مستوى (0.01) بين كل من العيات درجات

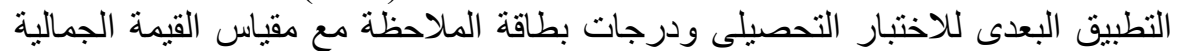
للكروشيه

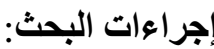
منهج البحث : البعت الباحثة منهجي الدراسة وهما: لتحديد أُوجيه القصيّي: التصور والضعف في منهج أشغال الإبرة (الكروشيه) المقدم للمرحلة

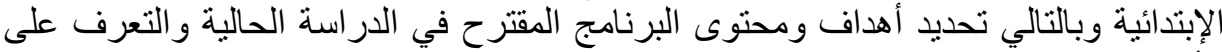

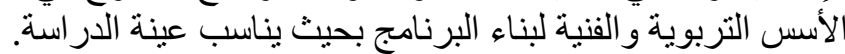

ذللك لتحديد فعالية برنامج مقترح قائم على أثخال الإبرة لتنمية التحصيل و القيم الجمالية

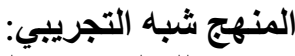

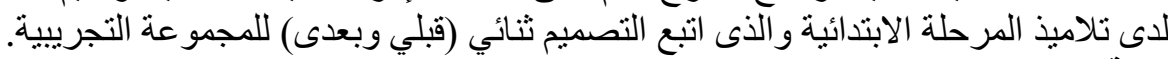

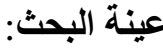

قامت الباحثة باختيار عينة الدراسة من تلاميذ المرحلة الابتدائية للعام الدراسي 2016-

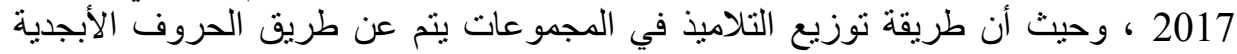

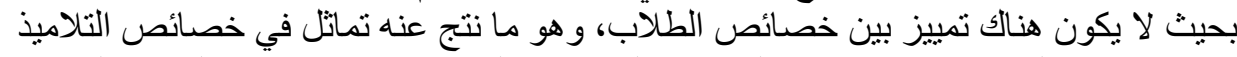

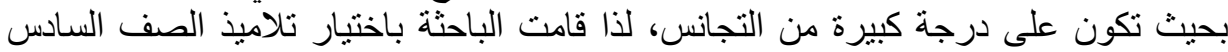

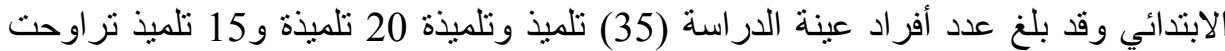
أعمار هم الزمنية ما بين

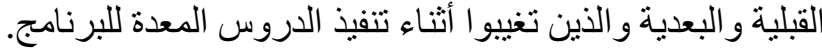
متفيرات الاراسة: يشتمل البحث على المتغير ات التالية:

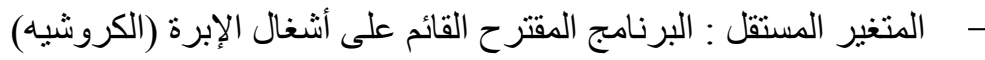

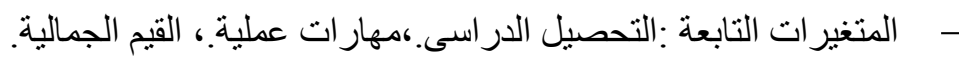

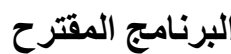
وتم إعداد تخطيط تفصيلى لدروس البرنامج المقترح بحيث يشتمل التخطيط لكل درس

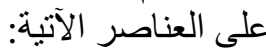
1. المدركات الأساسية للارس وتثنمل العناصر الرئيسية للادرس . 2. القضايا المتضمنة في الدرس ويجب أن تؤكد عليها المعلمة أثناء شرح الدئية الدرس لربط التعليم 


\section{مجلة الاقتصاد المنزلي ـ مجلا 27- العدد الثالث - 2017م}

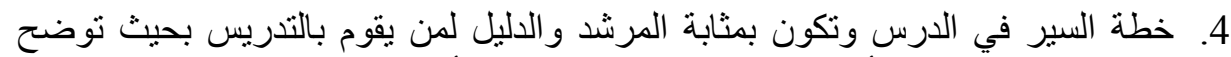

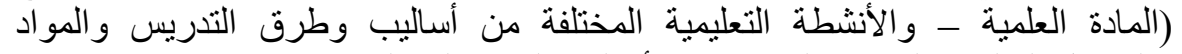

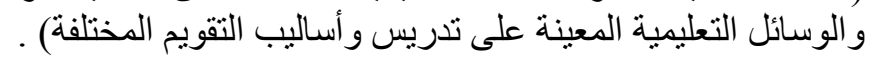

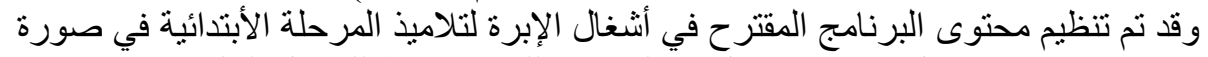

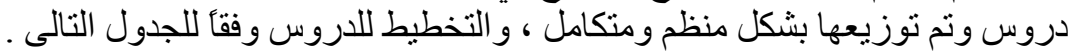
جدول(2) يوضح تنظيم موضون عات البرنامج المقترح

\begin{tabular}{|c|c|c|c|}
\hline الزمن الللازم & المدركات الأساسية & عنوان الارس & المسلسل \\
\hline اسبوع & $\begin{aligned} & 0 \\
& 0 \\
&\end{aligned}$ & فل الكرمة لتنفيذ الكروشيه والأدوات & الارس الأول \\
\hline اسبوع & 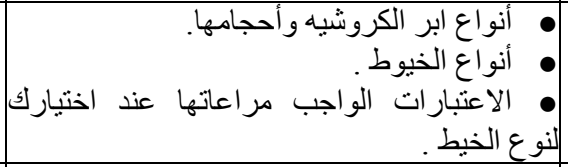 & اللابع الخامات لتنفيذ الكروشيه & 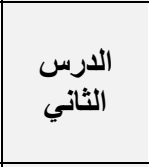 \\
\hline اسبوع & 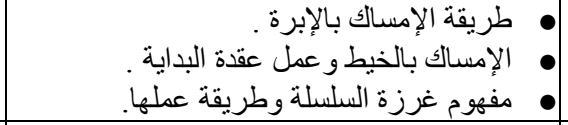 & طريقة عمل البداية في & 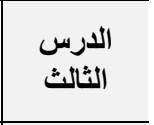 \\
\hline اسبوع & •غرزة الكروشيه المفردة القة . & طريقة عمل بعض غرز الكروشيه البسيطة & 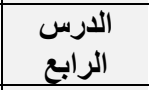 \\
\hline اسبوع & •غرزة النصف عمود (نصف مزدوجة) . & |تابع طريقة عمل بعض غرز البسيطة & 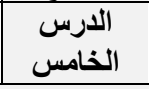 \\
\hline اسبوع & ] • الغرزة المزدوجة (العمود ذي اللفة الواحدة) . & |تابع طريقة عمل بعض غرز الكروشيه البسيطة & 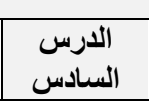 \\
\hline اسبوع & 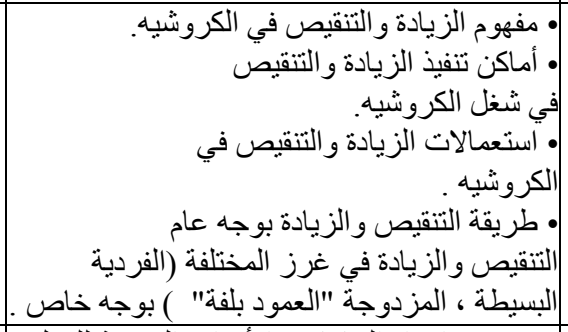 & الزيادة و التنقيص في & 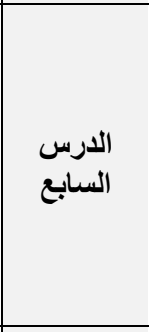 \\
\hline أربع اسابيع & • • تجفيذ المشغولة و إعداد الخامات وطريقة عملادوات . اللازمة للعمل . & تطبيقات في الكروشيه & 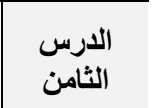 \\
\hline
\end{tabular}

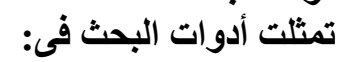

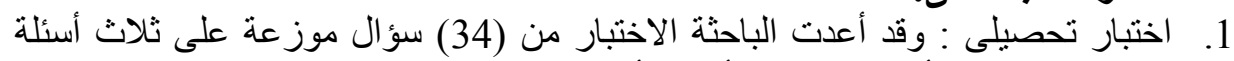

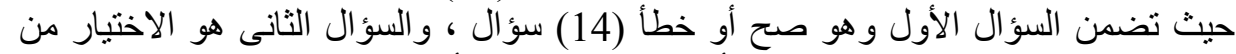

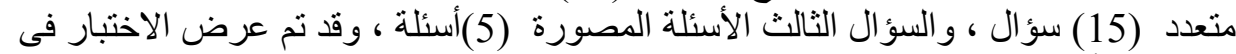

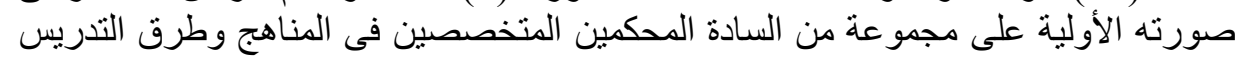

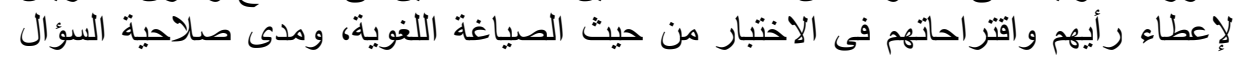




\section{مجلة الاقتصاد المنزلي - مجلد 27- العدد الثالث - 2017م}

لقياس ومدى مناسبة الاختبار لمستوى التلميذات. بعد ذللك تم تعديل ما تم اقتر احه من قبل السادة

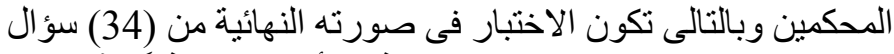

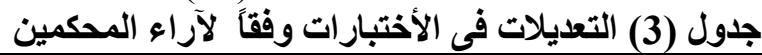

\begin{tabular}{|c|c|}
\hline & \\
\hline يه من أنو اع الكروشيه ـ ( ) & شيه (الفليه ، المروحة ، المعلقه \\
\hline أنها تستخدم الإبر الاستانلس عن الخيوط شائعة الأوزان ( ) ( ) منيو و البلاستيك ف & \\
\hline & تم إضافة \\
\hline 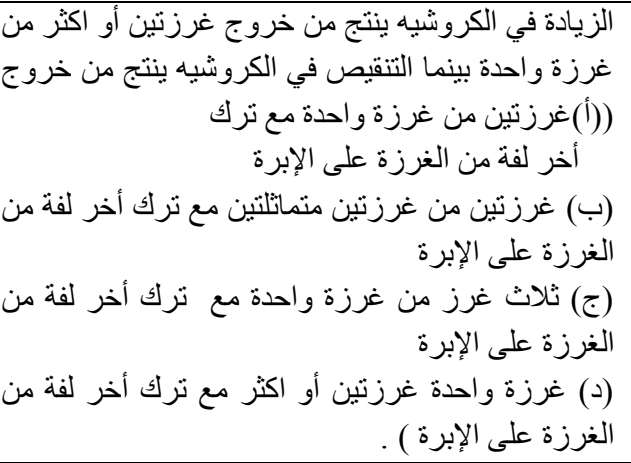 & 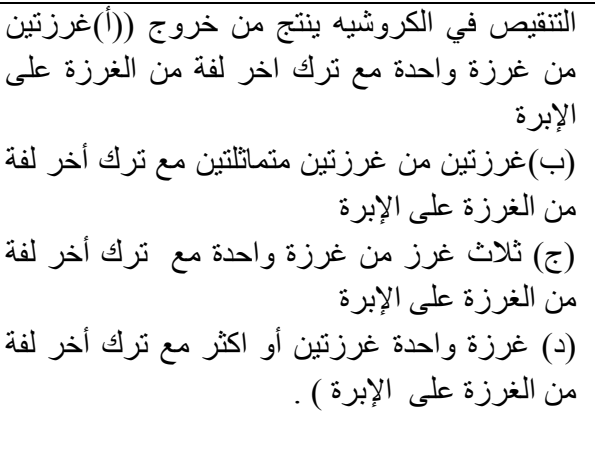 \\
\hline 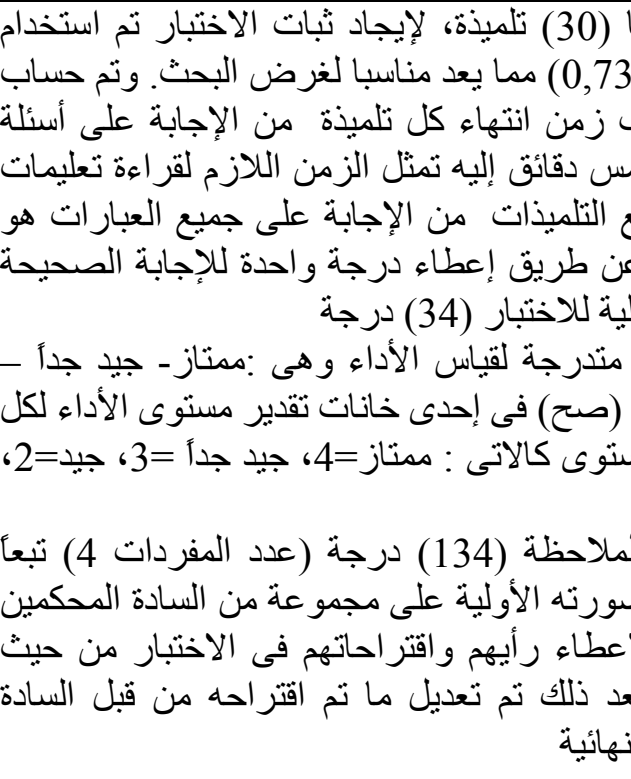 & 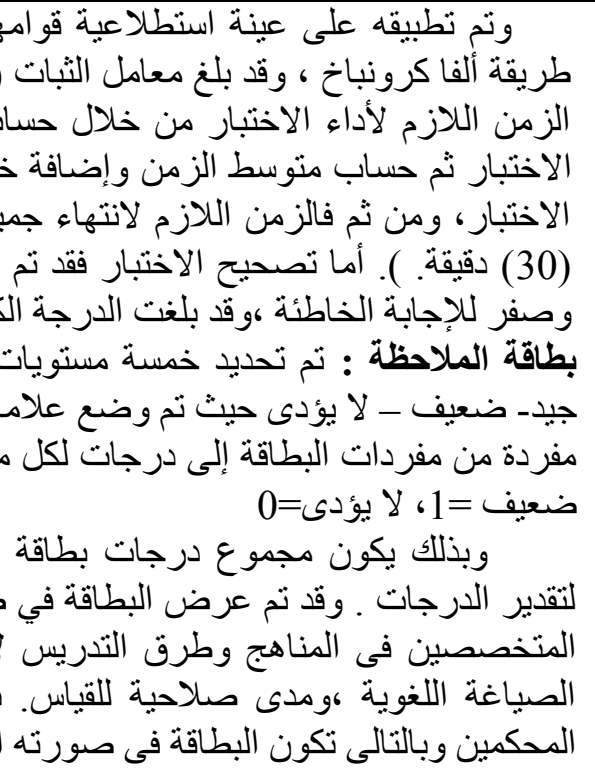 \\
\hline
\end{tabular}




$$
\text { مجلة الاقتصاد المنزلي - مجلد 27- العدد الثالث - 2017م }
$$

\section{جدول (4) التعديلات في بطاقة الملاحظة وفقاً لآراء المحكمين}

\begin{tabular}{|c|c|}
\hline المهارة بعد التعديل & المهارة قبل التعديل \\
\hline تختار الخيط المناسب لتنفيذ القطعة من حيث الخامة ، السمك ، و اللون & تختار الخيط المناسب لتنفيذ القطعة \\
\hline تمسك الإبرة بطريقة صحيحة اثناء العمل & تم إضافة \\
\hline
\end{tabular}

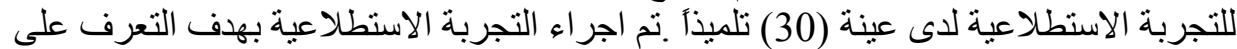

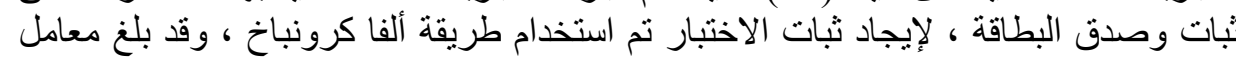

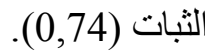

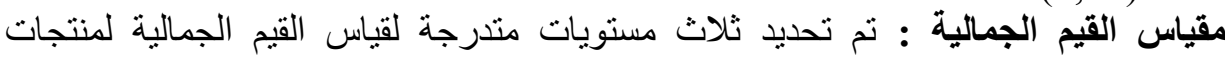

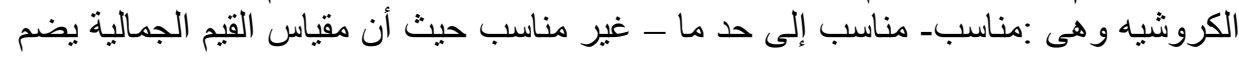

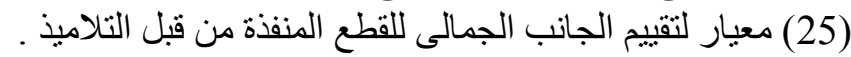

وقد قامت الباحثة بعد ذلك بتحديد درجات الإجابة على المقياس و هيى (3، 2، 1، 1) على الترتيب.

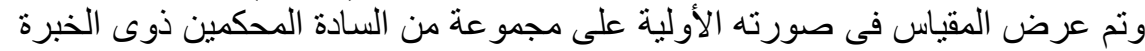

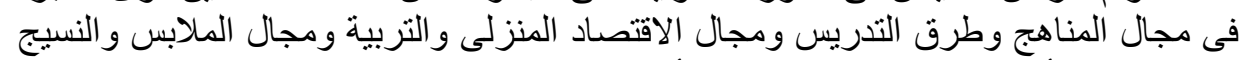

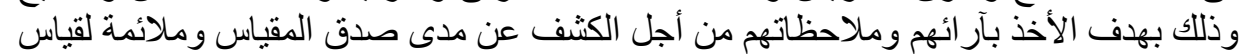

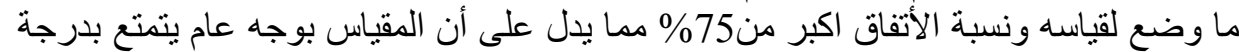

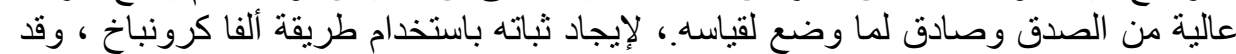

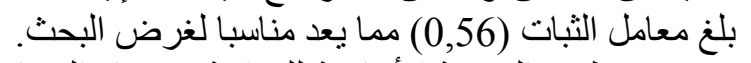

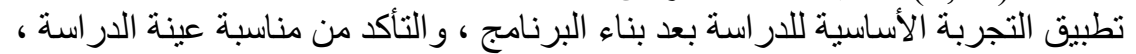

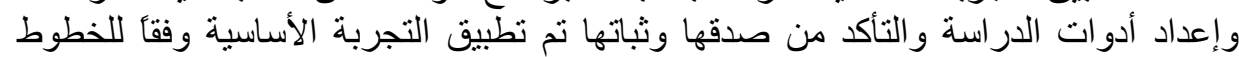

اختيرت مدرسة (منشأة بخاتى بنين (أ) بمدينة شبين الكوم) لكون عمل الباحثة فيها

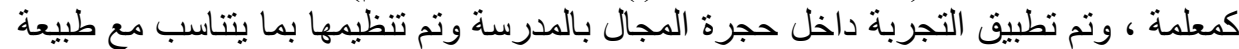

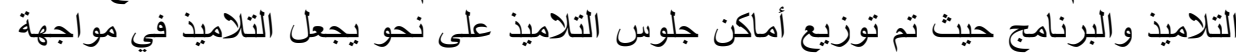

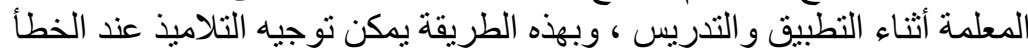

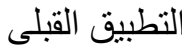

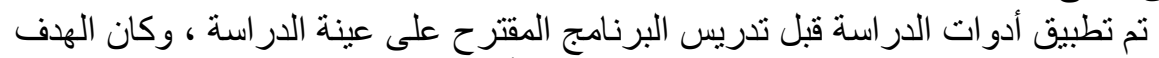

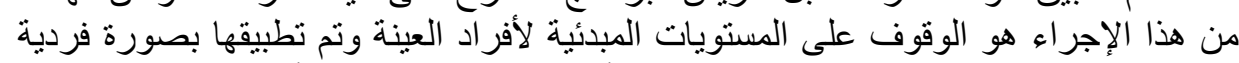

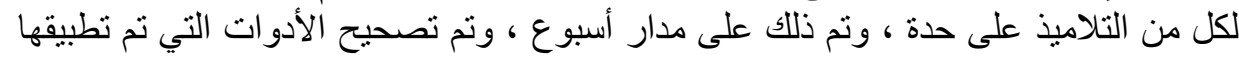

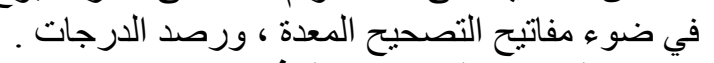
تدريس البرنامج المقترح خلال فترة :

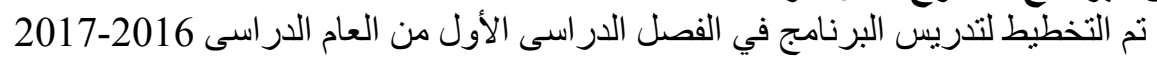

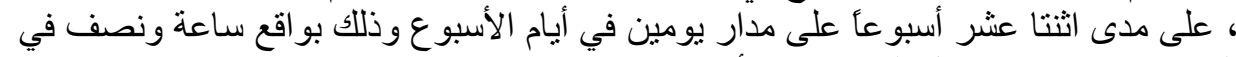

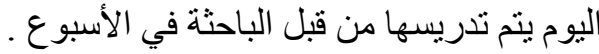


مجلة الاقتصاد المنزلي - مجلد 27- العدد الثالث - 2017م

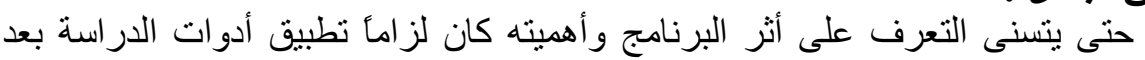

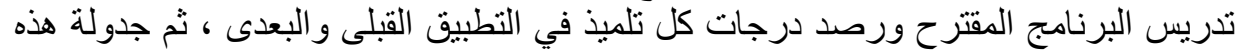

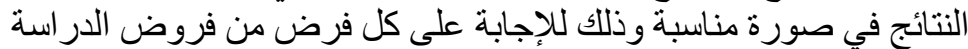

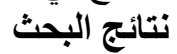
يتم عرض نتائج البحث وفق تسلسل فروضها كما يلى :

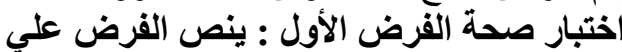

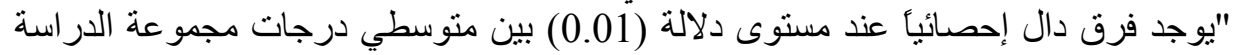
فى التطبيق القبلي ودرجاتهم فى التطبيق البعدى لاختبار التحنيل التصيل المعرفي بمستوياته جدول(5) الإحصاءات الوصفية لارجات التطبيقين القبلي والبعدي لصالح التطبيث البعدى." لاختبار التحصيل المعرفي.

\begin{tabular}{|c|c|c|c|c|c|c|c|}
\hline النهائية & درجة & درجة & الانحر افعياري & الحسابي & العدد & التطبيق & المستوي \\
\hline \multirow{2}{*}{10} & 10 & 8 & 0.58 & 9.69 & 35 & البعدي & \multirow{2}{*}{ التذكر } \\
\hline & 7 & 1 & 1.56 & 3.86 & 35 & القبلي & \\
\hline \multirow{2}{*}{9} & 9 & 6 & 0.77 & 8.60 & 35 & البعدي & \multirow{2}{*}{ الفهم } \\
\hline & 7 & 1 & 1.32 & 4.11 & 35 & القبلي & \\
\hline \multirow{2}{*}{8} & 8 & 6 & 0.51 & 7.83 & 35 & البعدي & \multirow{2}{*}{ التطبيق } \\
\hline & 4 & 1 & 1.06 & 2.60 & 35 & القبلي & \\
\hline \multirow{2}{*}{5} & 5 & 3 & 0.69 & 4.63 & 35 & البعدي & \multirow{2}{*}{ التحليل } \\
\hline & 3 & 0 & 0.89 & 1.54 & 35 & القبلي & \\
\hline \multirow{2}{*}{1} & 1 & 0 & 0.24 & 0.94 & 35 & البعدي & \multirow{2}{*}{ التركيب } \\
\hline & 1 & 0 & 0.44 & 0.26 & 35 & القبلي & \\
\hline \multirow{2}{*}{1} & 1 & 0 & 0.28 & 0.91 & 35 & البعدي & \multirow{2}{*}{ التقويم } \\
\hline & 1 & $\mathbf{0}$ & 0.51 & 0.51 & 35 & القبلي & \\
\hline \multirow{2}{*}{34} & 34 & 25 & 2.06 & 32.60 & 35 & البعدي & \multirow{2}{*}{ المعرفي } \\
\hline & 17 & 8 & 2.40 & 12.89 & 35 & القبلي & \\
\hline
\end{tabular}

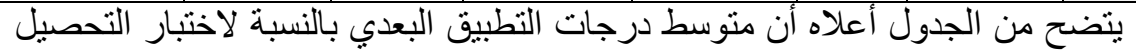

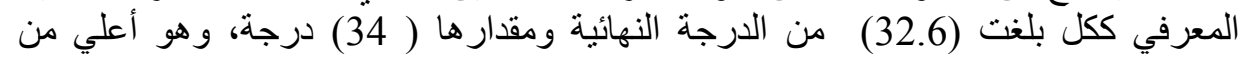

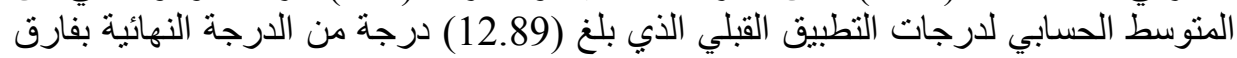

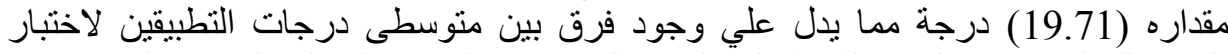

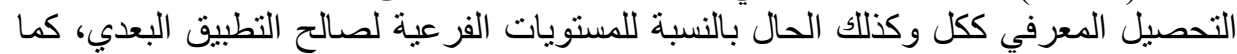

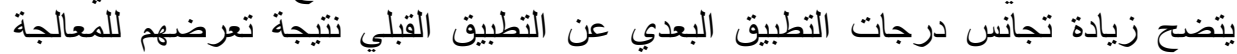
التجرييية (التدريس ببرنامج قائم علي أنشال الإبرة). وبتمثيل درجات التئي التطبيقين البحث باستخدام شكل الأعمدة البيانية اتضح ما يلي: 
مجلة الاقتصاد المنزلي - مجلد 27- العدد الثالث - 2017م

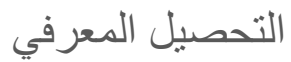

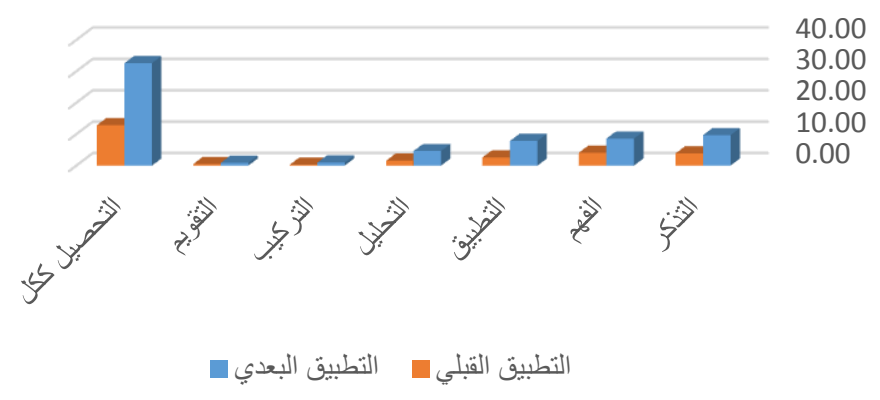

شكل (1) التمثيل البياني بالأعمدة لمتوسطات درجات التطبيقين

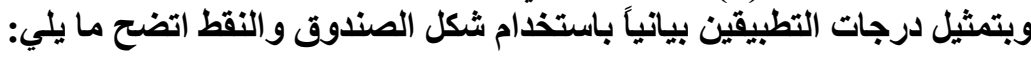

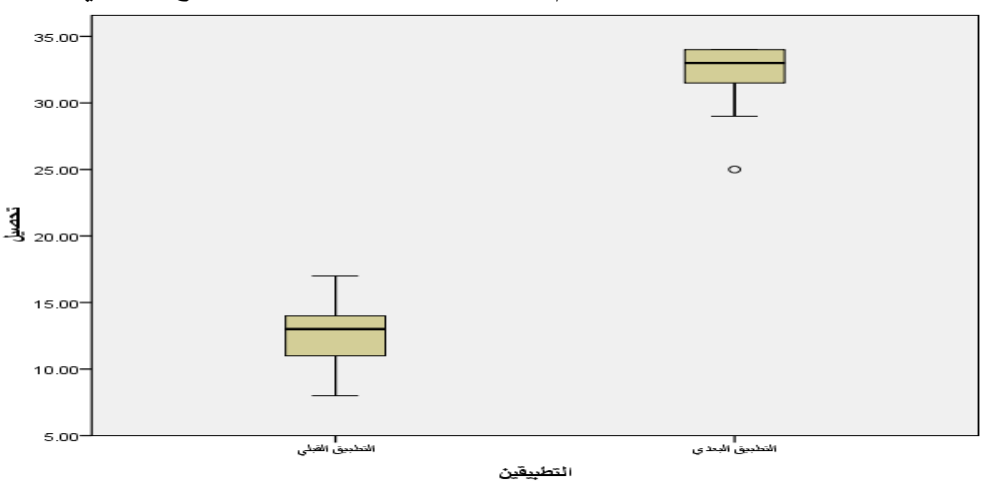

شكل (2) تمثيل الصندوق والنقطة لدرجات التطبيقين (التحصيل المعرفي)

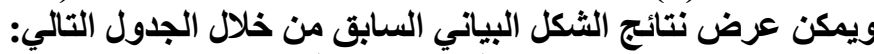

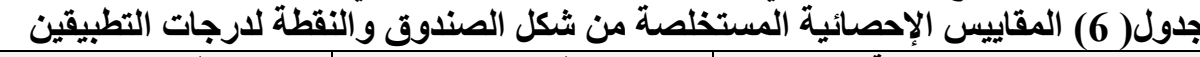

\begin{tabular}{|c|c|c|}
\hline التطبيق القبلي & التطبيق البعدي & المقاييس الإحصائية \\
\hline 8 & 25 & أقلّ درجةة \\
\hline 17 & 34 & أكبر درجة \\
\hline 11 & 31 & الربيع الأدنى \\
\hline 13 & 33 & الوسيط \\
\hline 14 & 34 & الربيع الأعلى \\
\hline
\end{tabular}

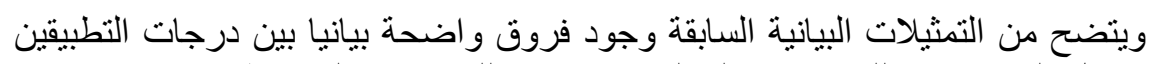

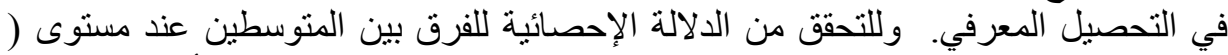

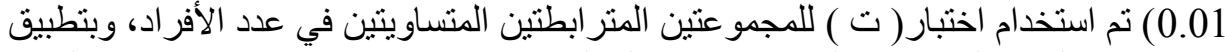
اختبار( ت) لفرق المتوسطين لقياس مقدار دلالة الفرق بين متوسطى درجات الفين مجمو عتي البحث

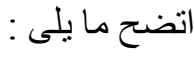


مجلة الاقتصاد المنزلي - مجلد 27- العدد الثالث - 2017م

جدول ( 7) نتائج اختبار " ت " للفرق بين متوسطي درجات التطبيقين في التحصيل المعرفي

\begin{tabular}{|c|c|c|c|c|c|c|c|}
\hline مستوية & مريع إيتا & مستوي & الحرية & قيمة & الانحراف المعياري & 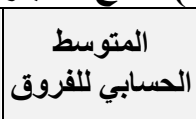 & المستوي \\
\hline وفاعلية كرتفعة & 0.92 & مستوي & 34 & 20.21 & 1.71 & 5.83 & التذكر \\
\hline وفاعلية كرتفعة & 0.89 & مستوي & 34 & 16.62 & 1.60 & 4.49 & الفهم \\
\hline وفاعلية مرتفعة & 0.96 & مستوي & 34 & 27.78 & 1.11 & 5.23 & التطبيق \\
\hline وفاعلية كرتفعة & 0.88 & مستوي & 34 & 15.57 & 1.17 & 3.09 & التحليل \\
\hline وفاعلية كرتفعة & 0.63 & مستوي & 34 & 7.66 & 0.53 & 0.69 & التركيب \\
\hline وفاعلية مرتفعة كبير & 0.35 & مستوي & 34 & 4.28 & 0.55 & 0.40 & التقويم \\
\hline |وفاعلية مرتفعة & 0.97 & مستوي & 34 & 33.62 & 3.47 & 19.71 & المعرفي ككيل \\
\hline
\end{tabular}

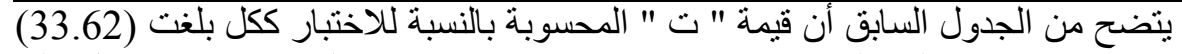

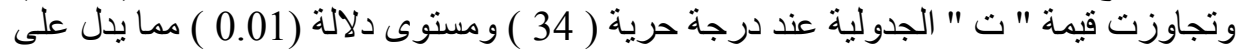

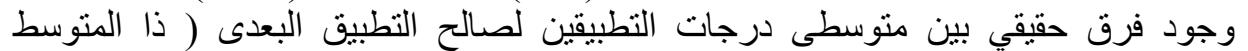

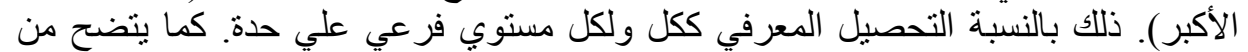

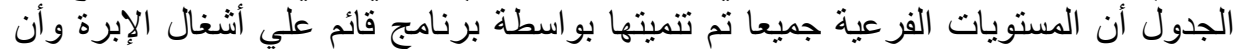

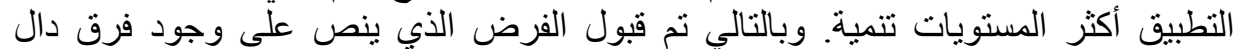

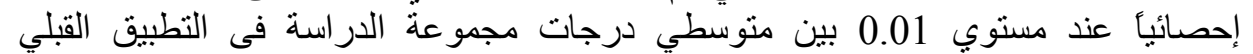

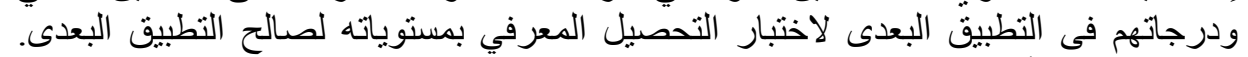

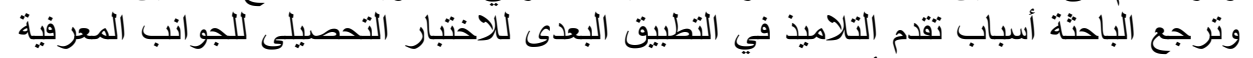

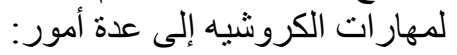

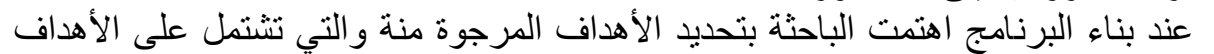

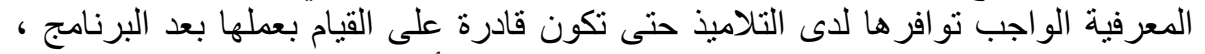

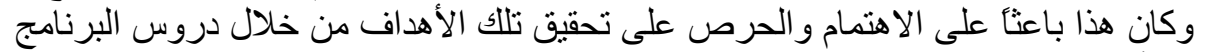

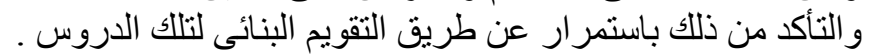

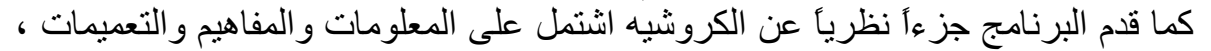

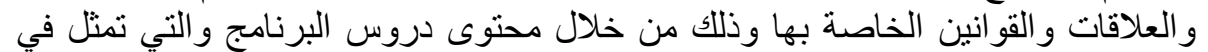

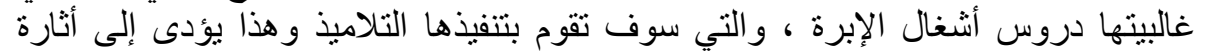

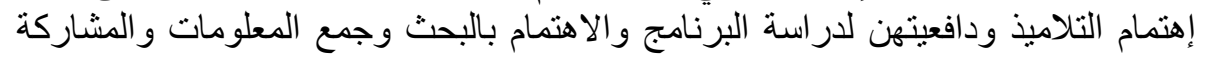

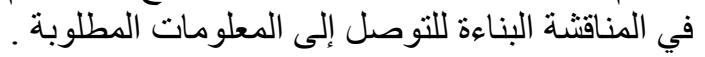

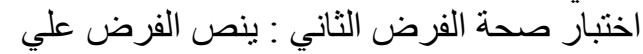

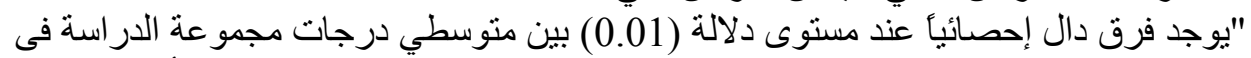
التطبيق القبلي ودرجاتهم فى التطبيق البعدى لبطاقة ملاحظة المهارات الأدائية لصالح 


\section{مجلة الاقتصاد المنزلي ـ مجلد 27- العدد الثالث - 2017م}

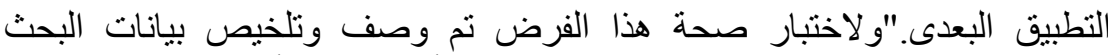

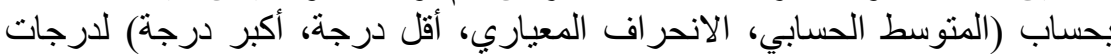

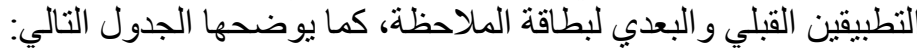
جدول(8) الإحصاء|ت الوصفية لارجات التطبيقين القبلي والبعدي لبطاقة الملاحظة.

\begin{tabular}{|c|c|c|c|c|c|c|c|}
\hline الأنهائة & أكبر درجة & أقل درجة & الانحراف المعياري & المستوسطي & العدد & التطبيق & المهارة \\
\hline \multirow[t]{2}{*}{16} & 16 & 14 & 0.66 & 15.49 & 35 & البعدي & \multirow[t]{2}{*}{ التخطيط } \\
\hline & 7 & 4 & 0.91 & 6.00 & 35 & القبلي & \\
\hline \multirow[t]{2}{*}{52} & 52 & 50 & 0.83 & 51.20 & 35 & البعدي & \multirow[t]{2}{*}{ التنفيذ } \\
\hline & 34 & 22 & 2.70 & 28.34 & 35 & القبلي & \\
\hline \multirow[t]{2}{*}{16} & 16 & 14 & 0.80 & 14.80 & 35 & البعدي & \multirow[t]{2}{*}{ الاتهاء } \\
\hline & 6 & $\mathbf{0}$ & 1.62 & 1.17 & 35 & القبلي " & \\
\hline \multirow[t]{2}{*}{84} & 84 & 79 & 1.60 & 81.49 & 35 & البعدي & \multirow{2}{*}{ الأدائية اليدوانبة } \\
\hline & 45 & 29 & 3.04 & 35.51 & 35 & القبلي & \\
\hline
\end{tabular}

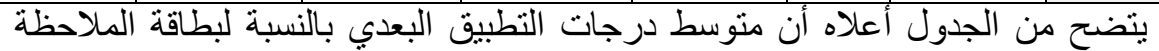

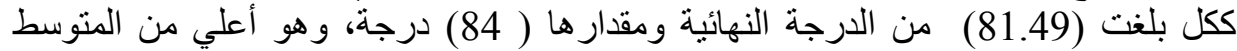

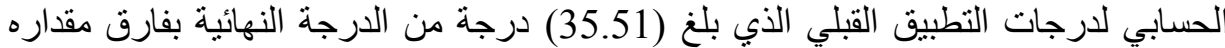

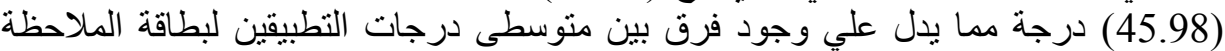

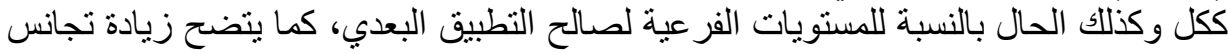

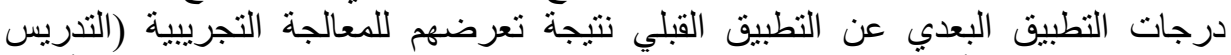
ببرنامج قائم علي أشغال الإبرة).وبتمثيل درجات التطبيقين البحثث باستخدام شكل الأعمدة

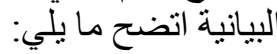

\section{بطاقة الملاحظة}

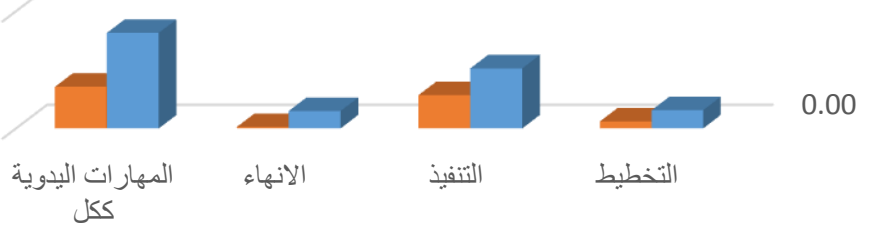

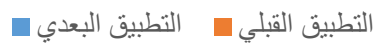

شكل ( 3 ) التمثيل البياني بالأعمدة لمتوسطات درجات التطبيقين 
مجلة الاقتصاد المنزلي - مجلا 27- العدد الثالث - 2017م

وبتمثيل درجات التطبيقين بيانياً باستخدام شكل الصندوق والنقط اتضح ما يلى:

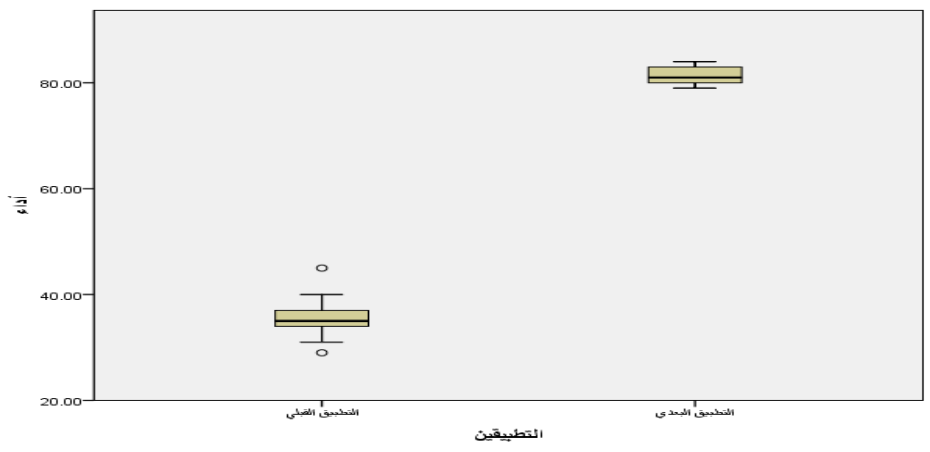

شكل ( 4) تمثيل الصندوق والنقطة لارجات التطبيقين (بطاقة الملاحظة التيات

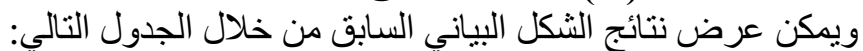

\begin{tabular}{|c|c|c|}
\hline التطبيق القبلي & التطبيق البعدي & المقاييس الإحصائية \\
\hline 29 & 79 & أقلّ درجة \\
\hline 45 & 84 & أكبر درجة \\
\hline 34 & 80 & الربيع الأدنى \\
\hline 35 & 81 & الوسيط \\
\hline 37 & 83 & الربيع الأعلى \\
\hline
\end{tabular}

ويتضح من التمثيلات البيانية السابقة وجود فروق واضحة بيانيا بين درجات التطبيقين

في الجو انب الأدائية.

جدول ( 10) نتائج اختبار " ت " للفرق بين متوسطي درجات التطبيقين لبطاقة الملاحظة

\begin{tabular}{|c|c|c|c|c|c|c|c|}
\hline مستوية & مربع إيتا & مستوي & الحرية & قيمة & المعياري & اللفرسابي & المستوي \\
\hline أثر كرتفير وفاعلية & 0.99 & مستوي & 34 & 51.27 & 1.09 & 9.49 & تخطيط \\
\hline أثركبير وفاعلية & 0.99 & مستوي & 34 & 51.74 & 2.61 & 22.86 & تنفيذ \\
\hline أثركبير وفاعلية & 0.98 & مستوي & 34 & 44.97 & 1.80 & 13.63 & انهاء \\
\hline أثركبير وفاعلية & 1.00 & مستوي & 34 & 95.29 & 2.85 & 45.97 & الملاحظة ككل \\
\hline
\end{tabular}

يتضح من الجدول السابق أن قيمة " ت " المحسوبة بالنسبة للبطاقة ككل بلغت (34) (95.29)

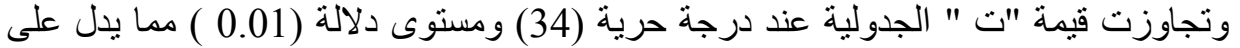

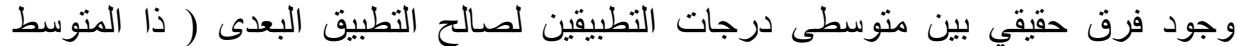

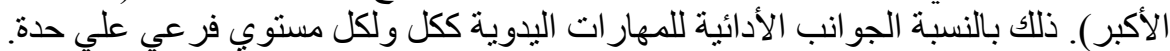




\section{مجلة الاقتصاد المنزلي ـ مجلا 27- العدد الثالث - 2017م}

كما يتضح من الجدول أن المستويات الفرعية جميعا تم تتميتها بواسطة برنامج قائم علي

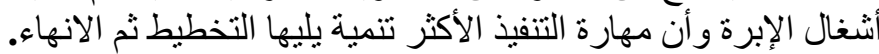

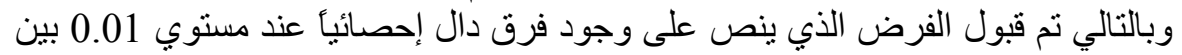

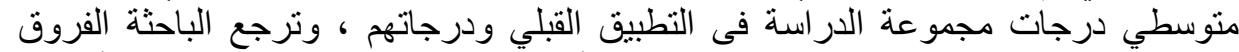
العالية بين التطبيق القبلى التطبيق البعدى في أداء التلميذ إلى التوجية السليم والأساليب التياتي

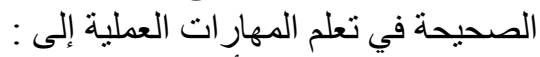

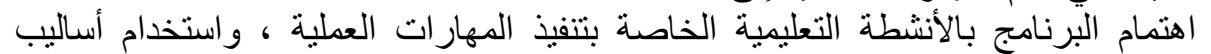

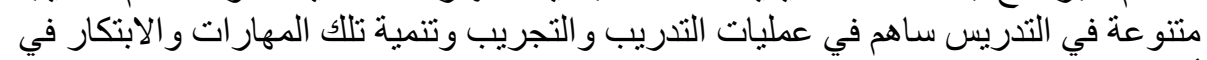
أدائها .

الاستفادة من ميول الطالبات واتجاهاتهن نحو البرنامج في تخطيط تعيينات عملية يقمن

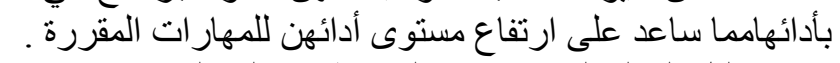

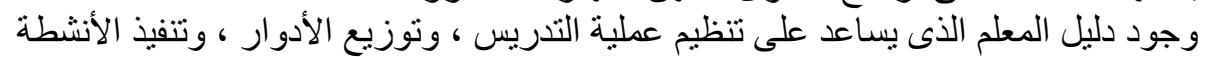

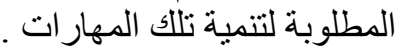

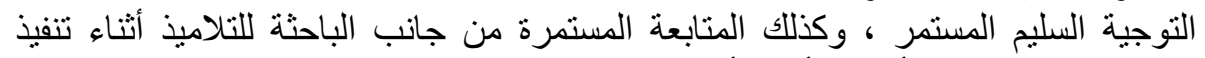

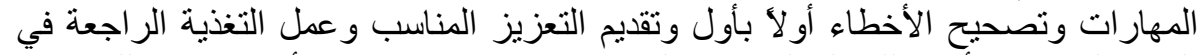

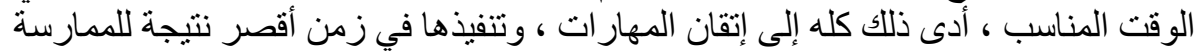

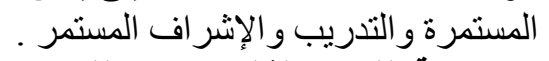

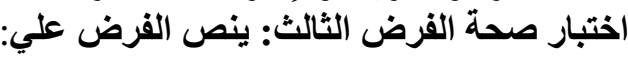

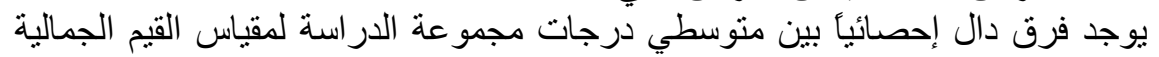

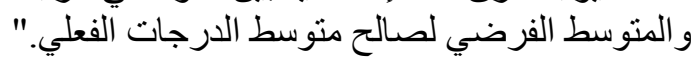

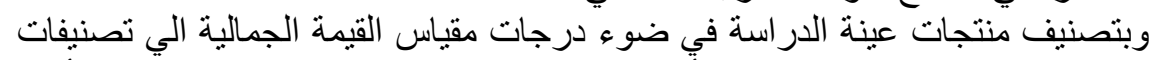

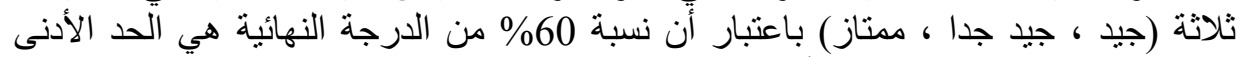

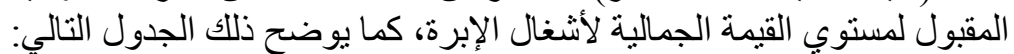

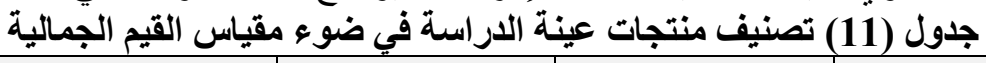

\begin{tabular}{|c|c|c|c|c|}
\hline المجموع & ممتاز(90\%) & جيد جدا(75\%) & جيد(60\%) & لمستوي الجمالى \\
\hline 75درجة & من 68 حتي75 & من 57 حتي67 & من 45 حتي56 & المدي بالدرجات \\
\hline 35 & 22 & 12 & 1 & العدد \\
\hline $100 \%$ & $62,9 \%$ & $34,3 \%$ & $2,9 \%$ & النسبة المئوية \\
\hline
\end{tabular}

حيث يبين الجدول أن مستوي القيم الجمالية متوفر بنسبة مرتفعة في منتجات عينة

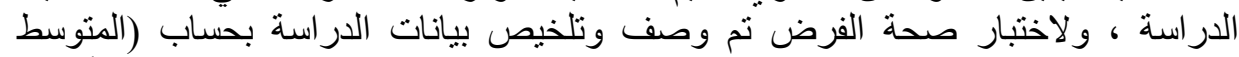

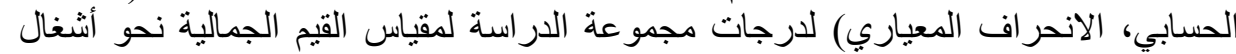

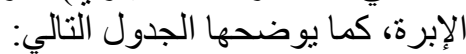

\section{جلول (12) الإحصاءات الوصفية لدرجات مقياس القيم الجمالية نحو أشغال الإبرة.}

\begin{tabular}{|c|c|c|c|c|}
\hline الدرجة النهائية & الانحراف المعياري & المتوسط الحسابي & العدد & المقياس \\
\hline 75 & 4,38 & 69,26 & 35 & القيم الجمالية \\
\hline
\end{tabular}

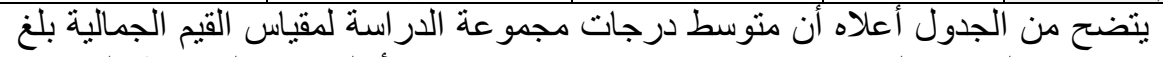

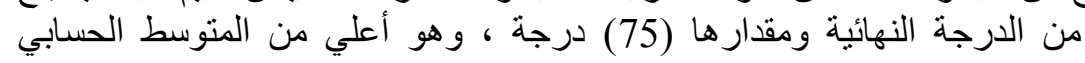




\section{مجلة الاقتصاد المنزلي - مجلد 27- العدد الثالث - 2017م}

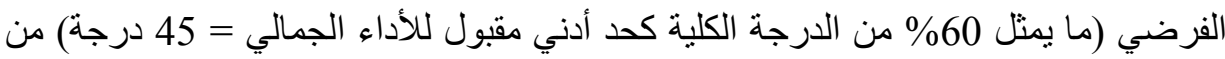
الدرجة النهائية بفارق مقداره $(24,26)$ درجة مما يدل علي وجود فرق بين النئ المنوسطين الفعلي

وللتحقق من الدلالة الإحصائية للفرق بين المنوسطين عند مسنوى ( 0,01) تم استخدام

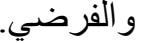

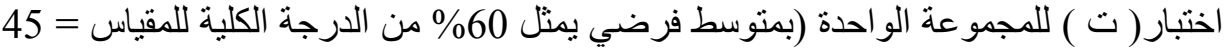

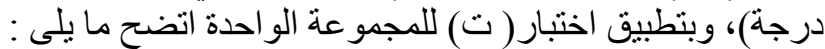
جدول (13) نتائج اختبار " ت " للمجموعة الواحدة للفرق بين المتوسطين الفعلي والفرضي في القيم الجمالية اللئر

\begin{tabular}{|c|c|c|c|c|c|c|}
\hline مستوي الفاعلية & مربع إيتا & مستوي & الحرية & قيمة ت & اللحسابي & المقياس \\
\hline أثر كبير وفاعلية & $\mathbf{0 , 9 7}$ & مستوي0101 & 34 & 32,754 & 24,26 & الجمألية \\
\hline
\end{tabular}

يتضح من الجدول السابق أن قيمة " ت " المحسوبة بالنسبة للمقياس بلغت (34, (32,754)

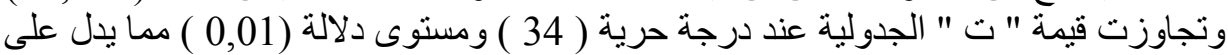

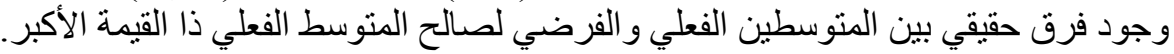

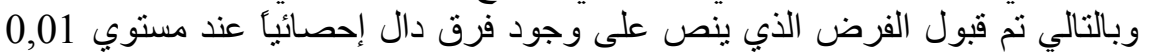

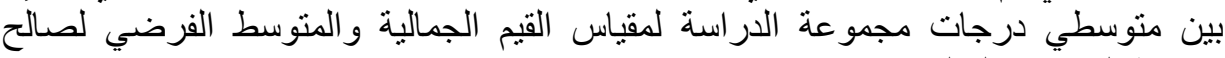
منوسط الدرجات الفعلي. يتضح من الجدول أن قيمة اختبار مربع إيتا(

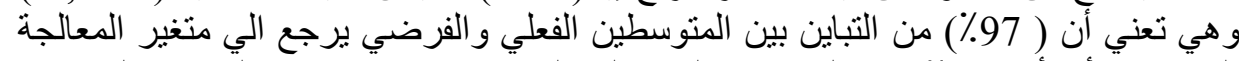

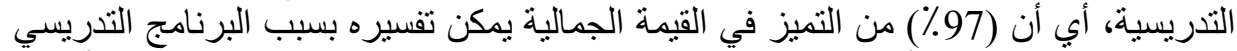

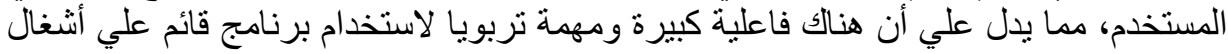

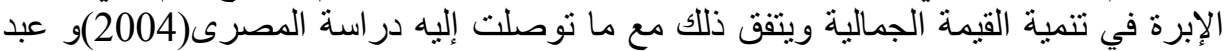

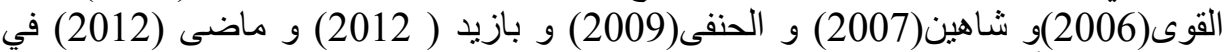

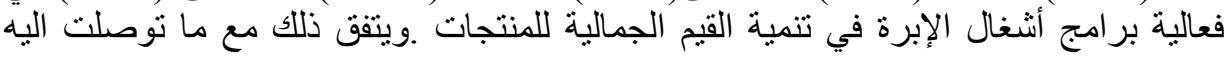

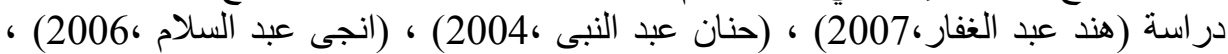

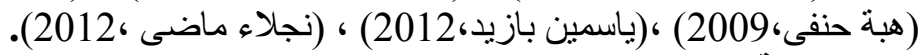
اختبار صحة الفرض الرابع: ينص الفرضين بازيد الفرض علي:

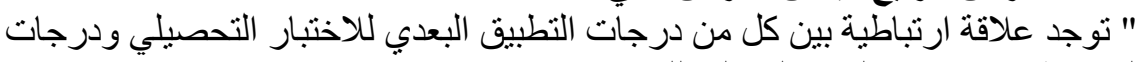

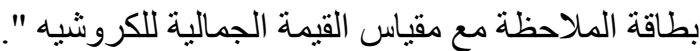

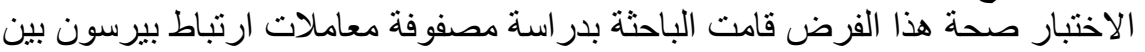

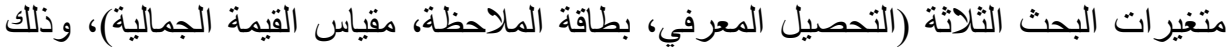

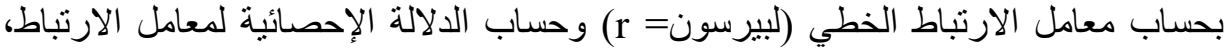

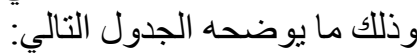


مجلة الاقتصاد المنزلي - مجلا 27- العدد الثالث - 2017م

جدل (14) مصفوفة معاملات الارتباط (للعلاقة بين التحصيل المعرفي وبطاقة الملاحظة

\begin{tabular}{|c|c|c|}
\hline المهارات العملية & التحصيل & المتغير \\
\hline--- & $0.677 * *$ & المهارات العملية \\
\hline $0.704 * *$ & $0.612 * *$ & القيمة الجمالية \\
\hline
\end{tabular}

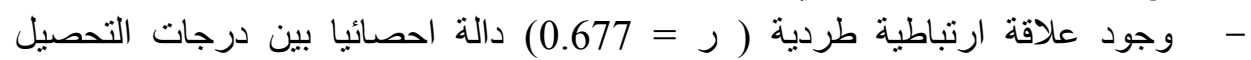
و الملاحظة للأداء العملي و المهار اتلة طلة اليدوية.

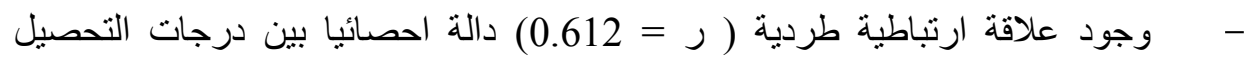
ومقياس القيمة الجمالية.

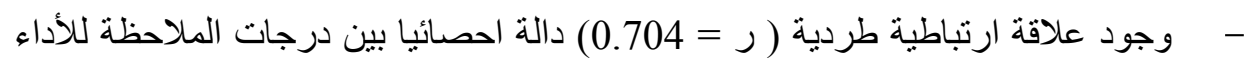
العملي ومقياس القيمة الجمالية. توصيات البحث

يوصىى البحث بعدد من التوصيات و المقترحات فى ضوء ما أسفرت عنه نتائج البحث من ضنمنها: ضرورة تطوير مناهج الاقتصاد المنزلى فى الجزء الخاص بأشغال الإبرة فى ضوء

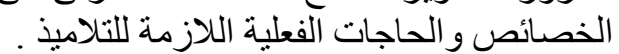

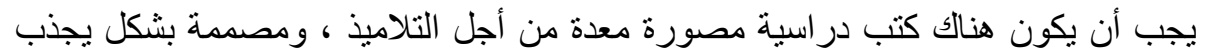

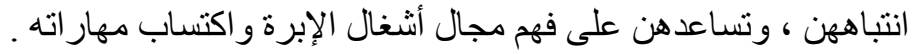

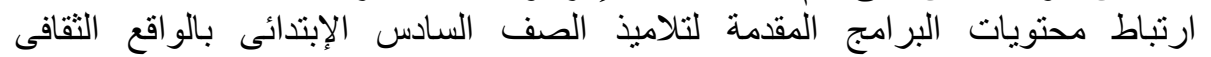

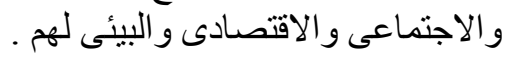

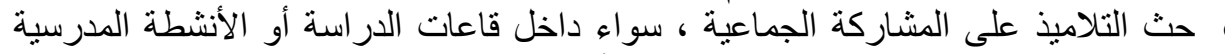

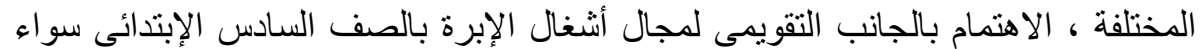

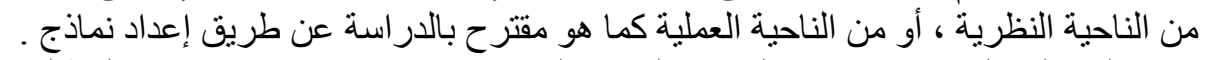

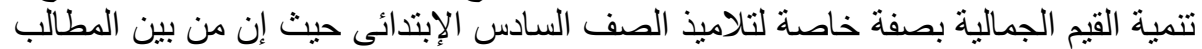

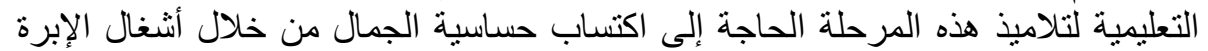

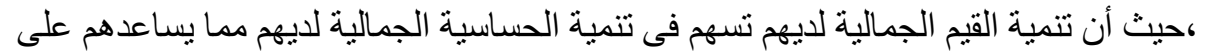

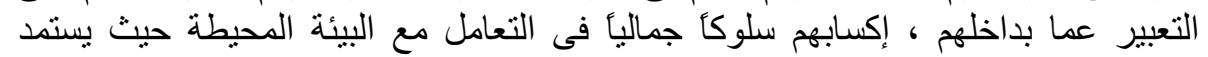

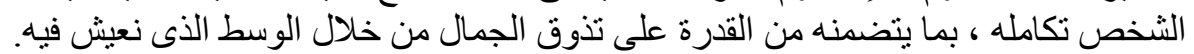

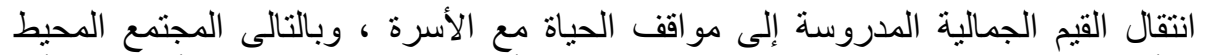

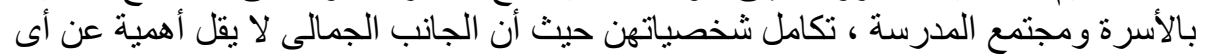

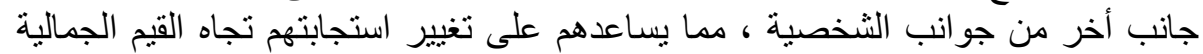

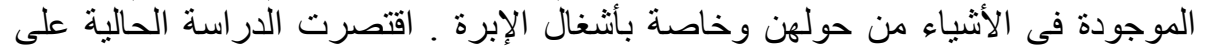

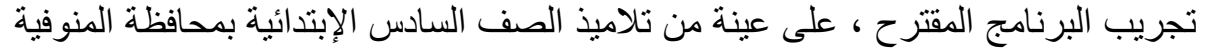
، يوصى بتجريب فعاليتة على مدارس أخرى بالمحافظات المختلفة بجمهورية مصر العربية. 


\section{مجلة الاقتصاد المنزلي ـ مجلا 27- العدد الثالث - 2017م}

1.احمد ، جيهان محمود عبد الحميد (2003) : تحليل القيم الجمالية للوحات الثتعبية المصرية

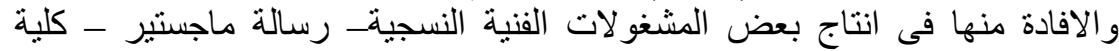

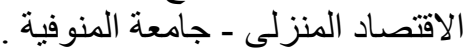

2.إسماعيل ، عصماء سمير محمد (2015) : القيم الجمالية والاقتصادية لأسلوب الترابر النسفير

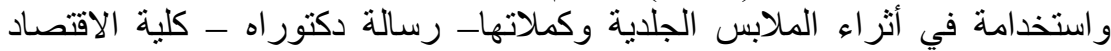
المنزلى - جامعة المنوفية .

3.الحنفى ، هبة فوزى (2009) : العلاقة بين نوع المنتج والخامة المستخدمة في منتجات

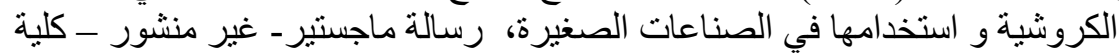

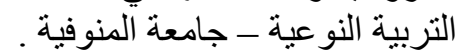

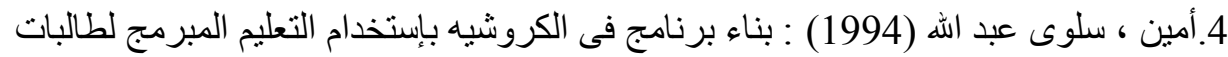

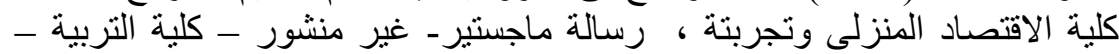

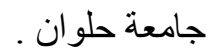
5.الفقى ، عبير محمد بيومى (2018) : استخدام بقايا الأقمشة كمدخل لإثراء جماليات ملابس

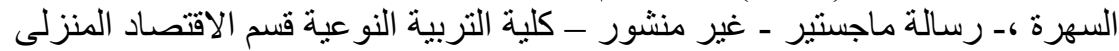

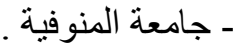

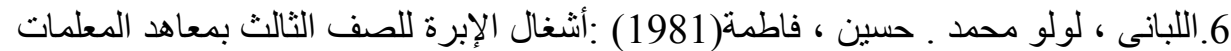

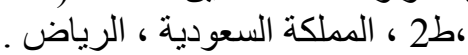

7.المهدى ، عنايات (1989) : فن الكروشيه الفلية ، مكتبة ابن سينا ، القاهرة الطبعة الأولى .

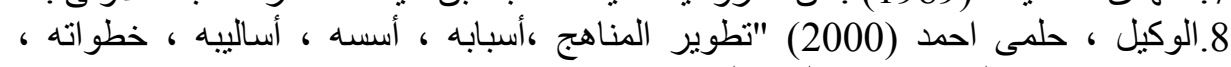

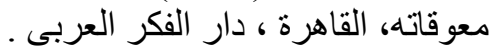

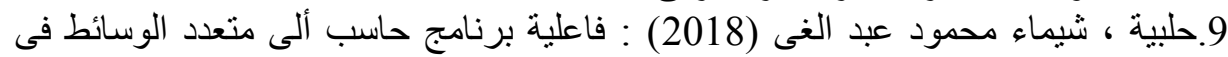

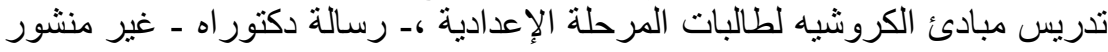

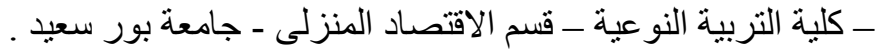
10.خيرى ، نجلاء (2009) : تعلمى فن الكروشيه أفكار جديدة ونماذج و أشكال مبتكرة من التئ

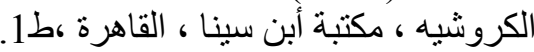

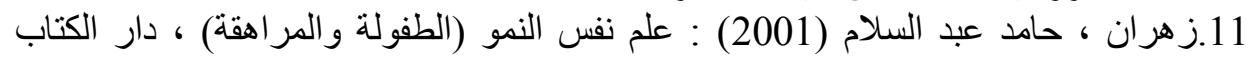

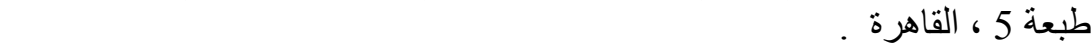
12.سعيد ، نرمين (2008) : أصول الكروشيه ، المركز العربى للنشر و التوزيع ، الأسكندرية .

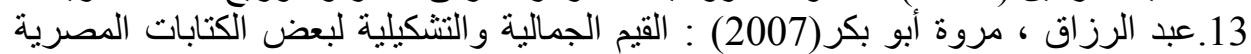

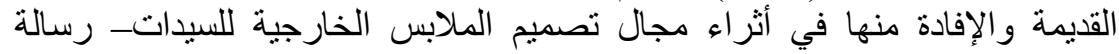

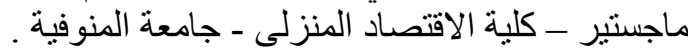

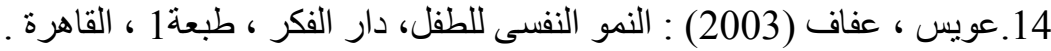

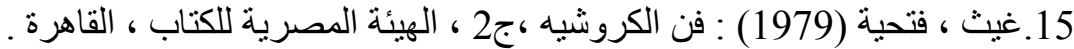

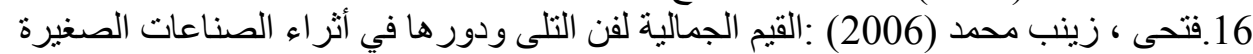

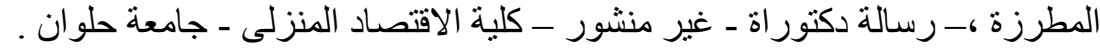

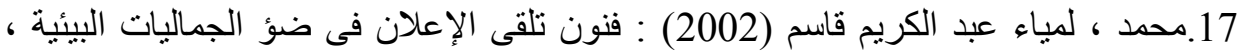

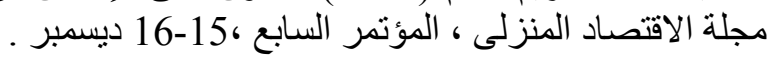


مجلة الاقتصاد المنزلي - مجلد 27- العدد الثالث - 2017م

18.مصطفى ، زينب عاطف (1999) : فاعلية برنامج للتمية بعض المهار ات العملية فى أنشغال

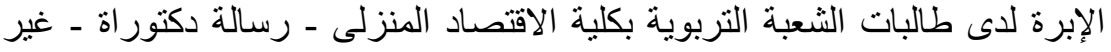

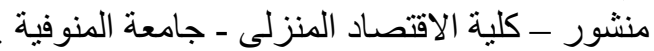

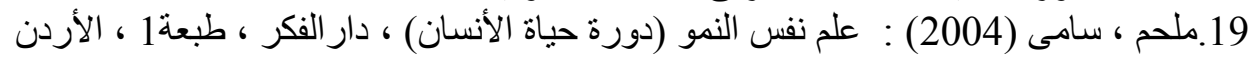

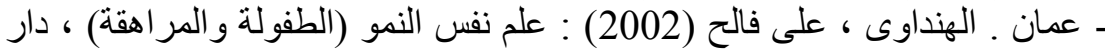

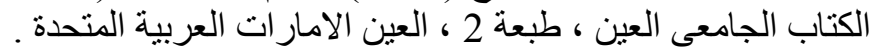

20.BBrittain, S., (2007) , Crochet patterns For Dummies, Wiley publishing, inc., Indianapolis Indiana .

21.IIbomu, A., (2006), get your crochet In : Hip hats \& cool caps , New town, ct. taunton, press Chain .

22.TTaylor,T., (2005) ,The new crochet : 40 wonderful wearables , Lark Books, New york .

23.SSullivan, C., A., (2008), Carry alongs 15 crochet hand bags \& purses for every occasion, Krause publications , inc., craft nourth America . 
مجلة الاقتصاد المنزلي - مجلا 27- العدد الثالث - 2017م

\title{
The Effectiveness of A Proposed Program Based on Knitting Work In Developing Achievement And Aesthetic Values Among Primary Stage Pupils
}

\author{
Roshdy Ali Ahmed Aeed ${ }^{(1)}$, Ahmed Hassan seif El Din ${ }^{(2)}$, Maha Jalal \\ Shoaib $^{(3)}$, yomna Salah Noor El Din ${ }^{(4)}$
}

The Professor and Head of Department of clothes and textiles, Faculty of Home Economics, Menoufiya University ${ }^{(1)}$,The Professor of curricula \& Teaching Methods in English language, Faculty of Education, Menoufiya University ${ }^{(2)}$,Dr, Department of Home Economics, Faculty of Home Economics, Menoufiya ${ }^{(3)}$. University Researcher of master ${ }^{(4)}$

\begin{abstract}
:
The purpos of the master: is to identify the effectiveness of a knitting work in development of achievement and aesthetic values among primary stage pupils .To achieve the objectives of the research a sample was selected from the elementary sixthgraders bakhaty facility school boys (a), the department of shebin al kom educational governorate of Menoufia. And research sample consisted of (35) of elementary sixthgraders, The research tools consisted in test experiment,a note card,measure of aesthetic values in crochet.

The reliability of each of the research tools was verified by presenting them to a group of arbitrators. The stability of the test was calculated in the Alpha Kronbach method. The stability coefficient of the test was 0.72 . The stability of the observation card was calculated by Alpha Kronbach, (0.74), and the stability of the value of the aesthetic value of crochet products was calculated by Alpha Kronbach method, and its value was the stability coefficient of the scale $(0.56)$ and therefore suitable for the purpose of the research.

Following the application of the research tools, the results indicated the effectiveness of the proposed program based on knitting work (crochet). The results resulted in:

A difference statistically significant at a level (0.1) between the experimental group grades Mediterranean tribal application and their grades in the application post to test cognitive achievement levels for application post.

1. A difference statistically significant at a level (0.01) between the experimental group grades Mediterranean tribal application and their grades in dimensional application note card.

2. The performing skills for application post.

3. A high level of aesthetic values of M3 and crochet products a difference statistically significant at a level (0.01) among middle grades study group for aesthetic values and medium scale proposition for the average grades.

4. The existence of a correlation function of a statistical function at a level (0.01) between each of the achievement test post application and degrees note card with the aesthetic value crochet.
\end{abstract}

Keywords: knitting work, crochet, achievement, aesthetic values. 